\title{
PREFABRICATED HOUSING SUBSIDY ANALYSIS IN CHINA BASED ON AN EVOLUTIONARY GAME MODEL
}

\author{
Kaicheng SHEN ${ }^{1}$, Xiaodong $\mathrm{LI}^{1}$, Xinying $\mathrm{CAO}^{2 *}$, Zhihui ZHANG \\ ${ }^{1}$ Department of Construction Management, School of Civil Engineering, Tsinghua University, Beijing, China \\ ${ }^{2}$ Department of Construction Management, School of Civil Engineering, Hainan University, Hainan Province, China
}

Received 12 February 2020; accepted 1 June 2021

\begin{abstract}
Prefabricated housing and cast-in-site housing are two alternatives for selection by developers and customers. The government, as the policy maker, creates incentive policies to encourage developers and customers to choose prefabricated housing. This paper aims to analyze the subsidy mechanism to theoretically confirm the subsidies' scopes, amounts and end times through an evolutionary game model and simulation. In the game model, government subsidies affect the interactions between developers and customers in the decision-making process. The findings are as follows: 1) The developer housing subsidy can lower the housing price, while the customer housing subsidy can increase the price; 2) The government should first offer the developers a larger subsidy amount during the early development stage and then offer the customers a smaller subsidy amount later; 3) The government should determine the end time based on the proportion of developers and customers who choose prefabricated housing; 4) A higher prefabrication ratio may not always improve the development of prefabricated housing, and there is an optimal production scale that creates the best development situation. The empirical analysis shows that this model can help the government develop reasonable and optimal subsidy policies within the limit of budget to stimulate developers and customers.
\end{abstract}

Keywords: prefabricated housing, subsidy, developer, customer, government, evolutionary game model.

\section{Abbreviations and parameters}

$\mathrm{PH}$ - prefabricated housing;

$\mathrm{CH}$ - cast-in-site housing;

DHS - developer housing subsidy;

CHS - Customer housing subsidy;

$\mathrm{C}_{f}$ - the cost to developers of developing $\mathrm{PH}$;

$R_{f}$ - developers' economic benefit from developing $\mathrm{PH}$;

$R_{e}$ - an extra benefit if developers choose $\mathrm{PH}$;

$\mathrm{C}_{t}$ - the cost to developers of developing $\mathrm{CH}$;

$R_{t}$ - developers' economic benefit from developing $\mathrm{CH}$;

$\mathrm{C}_{u}$ - the cost to customers of buying $\mathrm{PH}$;

$R_{u}$ - customers' benefit from $\mathrm{PH}$;

$\mathrm{C}_{c}$ - the cost to customers of buying $\mathrm{CH}$;

$R_{c}$ - customers' benefit from $\mathrm{CH}$;

$\mathrm{H}$ - the subsidy provided by the government for developers;

$F$ - the subsidy provided by the government for customers.

\section{Introduction}

Prefabricated housing $(\mathrm{PH})$ and cast-in-site housing $(\mathrm{CH})$ are two alternatives for developers and customers. $\mathrm{PH}$ is built using a construction method with a factory-produced prefabricated component, standardized design and mechanized manufacturing process (Xu \& Chen, 2010). Cast-in-site construction requires all the processes to be completed on site. Developers and customers have the right to decide which kind of housing they want, and their decisions form the housing market. In their work, developers focus on the costs and benefits, e.g., labor costs, technology, environment, reputation. Customers focus on prices and quality. The government, as the policy maker, adjusts the market via certain policy measures.

In recent years, the Chinese government has promoted $\mathrm{PH}$ to save labor costs and to improve productivity and quality. However, the development of PH in China still lags behind that in developed countries and other areas owing to high initial costs, lack of incentive policies, etc. (Zhang et al., 2014a, 2014b; Cao et al., 2015a; Li, 2020). Wang et al. (2018) found that assembly sequence plan-

*Corresponding author. E-mail: cxynews@outlook.com 
ning and technology can affect the quality, safety, schedule and costs of PH. Developers are driven by their own interests, so they are not willing to build $\mathrm{PH}$ at higher costs than $\mathrm{CH}$. Additionally, customers are not willing to spend higher prices on $\mathrm{PH}$ than $\mathrm{CH}$. Moreover, customers also care about the quality and performance of housing, and they know little about PH. The Chinese government has played an important role in the development of $\mathrm{PH}$. Incentive policies have been implemented in 25 provinces, and all these policies are oriented towards developers; only 4 provinces have also implemented customer housing policies. With the assistance of these policies, a set of data offered by the Ministry of Housing and Urban-Rural Development of the People's Republic of China [MOHURD] (2020) shows that the area of new prefabricated buildings in China increased from 114 million $\mathrm{m}^{2}$ in 2016 to 420 million $\mathrm{m}^{2}$ (13.4\% of area of the new buildings) in 2019 .

Although the government is devoted to promoting $\mathrm{PH}$ and has made certain incentive policies, there are no theories to support these policies. It is very complicated to analyze the transaction relationships between developers and customers. Moreover, it is difficult to design an optimal incentive measure to promote $\mathrm{PH}$. To develop $\mathrm{PH}$ faster, should those policies cater to developers or customers? There is still a theoretical demand to analyze the incentive mechanism and to confirm the subsidies' scopes, amounts and end times. The government needs to offer subsidies initially but should also determine when to stop because the government cannot provide subsidies continuously, given its financial expenditure limits. The government implemented a policy regarding construction area concessions for PH that began in 2010, stopped in 2011 (Beijing Municipal Commission of Housing and UrbanRural Development [BMCOHURD], 2010) and then was extended until 2015 (BMCOHURD, 2011) according to the situation of the PH market. Therefore, there is an urgent demand for the government to theoretically confirm the end time.

This study compares the differences in subsidies for developers and customers based on the characteristics of $\mathrm{PH}$ and helps the government decide which group has priority to obtain the subsidies, how much each group should receive, and when to stop these subsidies. A subsidy game model is built to analyze the incentive mechanism and the influences of governmental incentives. The paper indicates the leverage point to encourage both developers and customers to actively invest in $\mathrm{PH}$.

The subsidy game model for the $\mathrm{PH}$ market will cover the following aspects:

- Understanding the patterns of decision-making to achieve $\mathrm{PH}$ transactions;

- Analyzing the existence of subsidies affecting PH transactions by comparing the patterns of the subsidy for developers and customers;

- Confirming the scopes, amounts and end times of subsidies in terms of the equilibrium points and confirming a better kind of subsidy.
This study uses the subsidy game model as a theoretical approach and aims to ensure a reasonable and optimal way of stimulating developers and customers to choose $\mathrm{PH}$. This study aims to improve the efficiency in the decision-making processes of government subsidies. It also discusses the influence of costs on decision-making considering the prefabrication ratio and production scale. To achieve the aforementioned overall aims, the specific objectives of the paper are (1) to explore and compare the games played between developers and customers; (2) to analyze the amount of subsidies that should be offered and when to stop these subsidies by discussing the equilibrium points; and (3) to discuss and propose policy implications with a better understanding of $\mathrm{PH}$ subsidies.

\section{Literature review}

Subsidies are one of the most effective incentive policies and have been implemented in many fields. Fan and Dong (2018) used evolutionary game models with enterprises and consumers based on four government subsidy strategies for low-carbon diffusion and analyzed seven scenarios to provide related policy recommendations. Hong et al. (2019) analyzed the impact of government incentive measures on energy-saving behavior through random questionnaires and found that subsidy policies have a positive moderating effect between energy-saving attitudes and energy-saving behavior. Hassani et al. (2018) proposed an economic policy and statistical procedure to optimize fuel subsidy regimes to effectively manage pump prices and found that the subsidy mechanism has modular properties and technical and practical feasibility. Huang and $\mathrm{Wu}$ (2018) used a dynamic subsidy method for congestion management in distribution networks and showed that the method provided customers with cheap energy prices without a rebound effect. Casares et al. (2018) developed an endogenous growth model with a manufacturing and a nonmanufacturing sector and obtained the path of the optimal investment subsidy rate for the manufacturing sector in a market economy.

In terms of housing subsidies, several researchers have analyzed the influences of incentive systems on the housing market (Keser \& van Winden, 2000; Siqueira \& Sandler, 2004; Qian et al., 2015). Researchers have analyzed housing incentive policies and noted that housing subsidies should confirm the patterns and objects (Kemp, 2010), the admittance criteria (Jia, 2016), and the standards and scope for developers and customers (Zheng et al., 2014). However, there are few studies of the PH market. Jia (2013) used an evolutionary game model of the government, developers and customers to analyze the incentive mechanism of the $\mathrm{PH}$ market and recommended that the government play a leading role at the early stage of the development of PH to offer certain material incentives.

Although there are some studies on subsidies and housing subsidies, those studies have several limitations, 
which require further investigation with some caution. The limitations include the following:

- There are few studies on the incentive mechanism of the PH market. Most current studies focus on the manufacturing sector and energy sector, and even those on the housing market mainly focus on green housing and public housing. $\mathrm{PH}$ is different from green housing and public housing, which is characterized by manufacturing and construction. Governmental incentives are required to improve the development of PH.

- Recent studies have analyzed the impacts, scopes, patterns and standards of subsidies. However, there is still a lack of research on the length of the subsidy and when the policy should end. The government has no clear standards or policies to determine the end times. Therefore, it is important for the government to improve the development of $\mathrm{PH}$ and to reduce expenditures.

Additionally, relationships between parties and their interactions are usually neglected. Therefore, this paper analyzes the interactions between developers and customers in the PH market through a game theory approach and the impact of government subsidies to confirm the scopes, amounts and end times of subsidies.

\section{Evolutionary game model}

Developers and customers both create strategies on which kind of buildings they need to choose. The government also needs to decide which subsidies should be provided. Game theory is a conflict management tool that deals with disputes between decision-makers and is used to analyze strategies, interactions and equilibrium solutions (Khanzadi et al., 2016).

Traditional game theory is based on the condition that people are entirely rational and all pursue the maximum individual benefits. However, according to their knowledge and logical reasoning ability, people have limits in rationality when they are dealing with complicated problems. The evolutionary game model is a generic approach to evolutionary dynamics, including a special case constant, fitness landscape and selection (Roca et al., 2009). It considers that the participants are bounded rational and imitate and learn from other people to find the optimal strategies (Gu et al., 2018). Scholars have applied the evolutionary game model to $\mathrm{PH}$, the green building market and green supply chain analysis (Xing \& Deng, 2017). Developers and customers are boundedly rational participants when choosing between $\mathrm{PH}$ and $\mathrm{CH}$. They cannot discover changes in the environment and make the correct choice all the time. They think only about short-term utility when they adjust their strategies (Xing \& Deng, 2017). Therefore, the evolutionary game model is a suitable methodology in this paper.

The evolutionary game model originates from Darwinian evolution and combines game theory with dynamics.
Two kinds of analysis frameworks are most frequently used, i.e., best response dynamics and replicator dynamics (Jia, 2013). The best response dynamics model is aimed at small groups that have a higher rationality level and fast learning speed. Small groups can quickly adjust strategies based on the previous game. The replicator dynamics model is aimed at large groups that have a lower rationality level and simple simulation ability. When the adaptability of a strategy is better than the average level in the group, which means that the payment of this strategy is higher than that of other strategies, the participants who choose other strategies will try to imitate and learn more from this strategy. Then, they will gradually adopt a better strategy. In this study, developers and customers as large groups always imitate and learn from each other to obtain a better optimal strategy. Thus, the replicator dynamics model is applicable to this research.

The replicator dynamics model is based on an infinite and mixed homogeneous population. It is assumed that there are $n$ individuals in a population, and each individual $i$ has an action $a_{i}$; then, the action set is $A=\left\{a_{1}, a_{2}, \cdots, a_{n}\right\}$. There are $k$ strategies in this population, and the strategy set is $S=\left\{x_{1}, x_{2}, \cdots, x_{k}\right\}$. Then, the payment of $x_{i}$ is $\pi_{i}$, and the payment set is $\Pi=\left\{\pi_{1}, \pi_{2}, \cdots, \pi_{k}\right\}$. At moment $t$, the proportion of strategy $x_{i}$ in the group is $P=\left\{p_{1}, p_{2}, \cdots, p_{k}\right\}$. Then, the whole expected revenue is shown as Eqn (1):

$$
E=\sum_{i=1}^{k} p_{i} \pi_{i} .
$$

As time goes by, $P$ will change, and the changing rate of $p_{i}$ is proportional to its value and adaptability. In other words, the larger $p_{i}$ is, the more the strategy influences other individuals. Compared to the individuals who choose other strategies, the population prefers to choose $x_{i}$; then, they learn more quickly, and their payments have more advantages. The strategy adjustment rate can be indicated by the replicator dynamics equation, as shown in Eqn (2):

$$
\frac{d p_{i}}{d t}=p_{i} \pi_{i}-E
$$

When the adjustment rate is 0 and the replicator dynamics equation is 0 , the evolution reaches the steady state. Individuals continue choosing and adjusting strategies until most members of the population choose a certain strategy to reach the steady state, and there are no mutated strategies that can have higher adaptability or payment. Then, this certain strategy is called the evolutionary stabilization strategy (ESS).

\section{Model analysis}

\subsection{Model assumption}

In this paper, there are three stakeholders: the government, developers and customers. Developers and customers choose between $\mathrm{PH}$ and $\mathrm{CH}$. The government plays the role of a policy maker that can influence the whole $\mathrm{PH}$ 
market. $\mathrm{PH}$ and $\mathrm{CH}$ are two alternatives in the housing market that can be selected by developers and customers (Figure 1). Therefore, the subsidy objects are the developers and customers who choose PH. There are two subsidy patterns, i.e., the developer housing subsidy (DHS) and the customer housing subsidy (CHS). According to the literature review (Cao et al., 2015b; Jia, 2013) and a survey on the current situation in China, the model assumptions are as follows:

(1) Developers have two strategies \{developing PH, developing $\mathrm{CH}$, and customers also have two strategies \{buying $\mathrm{PH}$, buying $\mathrm{CH}$.

(2) $C_{f}$ is the cost to developers of developing PH. Developers can obtain an economic benefit $R_{f}$ and an extra benefit $R_{e}$ if they choose $\mathrm{PH}$, e.g., social and environmental benefits.

(3) $C_{t}$ is the cost to developers of developing $\mathrm{CH} . R_{t}$ is the economic benefit from developing $\mathrm{CH}$.

(4) $C_{u}$ is the cost to customers of buying $\mathrm{PH}$, and $R_{u}$ is the benefit.

(5) $C_{c}$ is the cost to customers of buying $\mathrm{CH}$, and $R_{c}$ is the benefit.

(6) $H$ is the subsidy provided by the government for developers if developers choose to develop PH.

(7) $F$ is the subsidy provided by the government for customers if customers choose to buy $\mathrm{PH}$.

(8) If the developers develop PH but the customers want to buy $\mathrm{CH}$, then the transaction fails. Both developers and customers have no economic benefits, and the developers have cost $C_{f}$, and vice versa. If the developers develop $\mathrm{CH}$ but the customers want to buy $\mathrm{PH}$, then the transaction fails. Both developers and customers have no benefits, and the developers have cost $C_{t}$.

(9) During the early development of $\mathrm{PH}$ in China, $\mathrm{PH}$ costs more than $\mathrm{CH}$, and its price is also higher. However, PH has social and environmental benefits and is of high quality, as mentioned in the introduction. Therefore, it is assumed that $C_{f}>C_{t}$, $R_{f}>R_{t}, C_{u}>C c, R_{u}>R_{c}$, and $R_{e}>0$. The mentioned benefits do not include the benefits of subsidies.

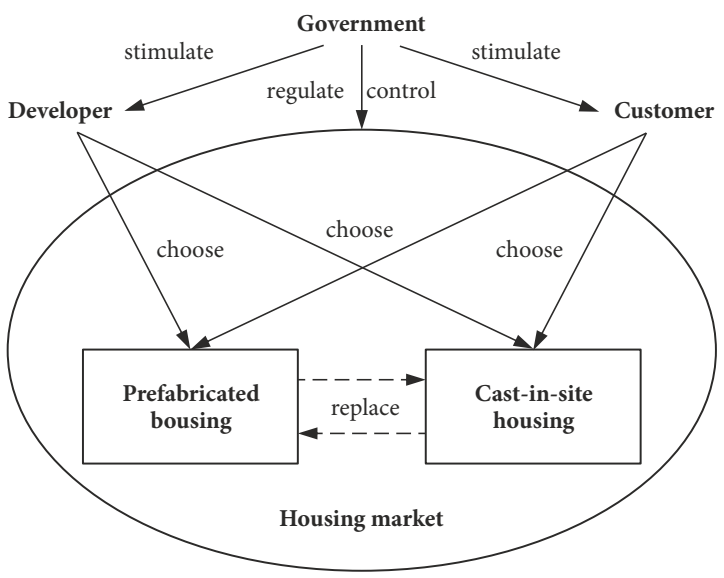

Figure 1. Housing market for $\mathrm{PH}$ and $\mathrm{CH}$

\subsection{Revenue analysis}

If the government provides no subsidy, the payment matrix of the developers and customers is as shown in Table 1.

Table 1. Payment matrix between developers and customers without subsidies

\begin{tabular}{|c|l|l|}
\hline \multirow{2}{*}{ Developer } & \multicolumn{2}{|c|}{ Customer } \\
\cline { 2 - 3 } & \multicolumn{1}{|c|}{$\mathrm{PH}$} & $\mathrm{CH}$ \\
\hline $\mathrm{PH}$ & $\left(R_{f}+R_{e}-C_{f} R_{u}-C_{u}\right)$ & $\left(R_{e}-C_{f}, 0\right)$ \\
\hline $\mathrm{CH}$ & $\left(-C_{t}, 0\right)$ & $\left(R_{t}-C_{t}, R_{c}-C_{c}\right)$ \\
\hline
\end{tabular}

The probability that developers will develop $\mathrm{PH}$ is $x$, and the probability that developers will develop $\mathrm{CH}$ is $1-$ $x$, the probability that customers will buy $\mathrm{PH}$ is $y$, and the probability that customers will buy $\mathrm{CH}$ is $1-y$.

Then, the developers' revenue from developing $\mathrm{PH}$ is shown in Eqn (3):

$U_{f}=y\left(R_{f}+R_{e}-C_{f}\right)+(1-y)\left(R_{e}-C_{f}\right)=y R_{f}-C_{f}+R_{e}$.

The developers' revenue from developing $\mathrm{CH}$ is shown in Eqn (4):

$$
U_{t}=y\left(-C_{t}\right)+(1-y)\left(R_{t}-C_{t}\right)=-y R_{t}+R_{t}-C_{t} .
$$

Only if $U_{f}>U_{t}$, do developers want to develop PH.

Let $\Delta_{1}=U_{f}-U_{t}=\left(R_{f}+R_{t}\right) y+R_{e}-R_{t}+C_{t}-C_{f}=0$, then $y^{*}$ is shown in Eqn (5):

$$
y^{*}=\frac{R_{t}-R_{e}+C_{f}-C_{t}}{R_{f}+R_{t}} .
$$

At this time, if the customers have a probability of $y^{*}$, developers have the same revenue from $\mathrm{PH}$ and $\mathrm{CH}$. If customers have a probability larger than $y^{*}$, developers will choose to develop PH.

If the government provides subsidy $H$ for developers, then developers will obtain extra $H$ when developing PH. The new revenue is shown in Eqn (6):

$$
\begin{aligned}
& U_{f}^{\prime}=y\left(R_{f}+R_{e}-C_{f}+H\right)+(1-y)\left(R_{e}-C_{f}+H\right)= \\
& y R_{f}-C_{f}+R_{e}+H .
\end{aligned}
$$

The revenue of developing $\mathrm{CH}$ is still the same.

Then,

$\Delta_{1}^{\prime}=U_{f}^{\prime}-U_{t}=\left(R_{f}+R_{t}\right) y+R_{e}-R_{t}+C_{t}-C_{f}+H=0$,

and

$$
y^{\prime}=\frac{R_{t}-R_{e}+C_{f}-C_{t}-H}{R_{f}+R_{t}}<y^{*} .
$$

If customers have a greater probability than $y^{\prime}$, developers will choose to develop PH. The shadow in Figure 2 shows the willingness to choose $\mathrm{PH}$. Figure 2 shows that $y^{\prime}<y^{*}$, which means developers choose $\mathrm{PH}$ under the condition that customers have a low probability of choosing $\mathrm{PH}$. 


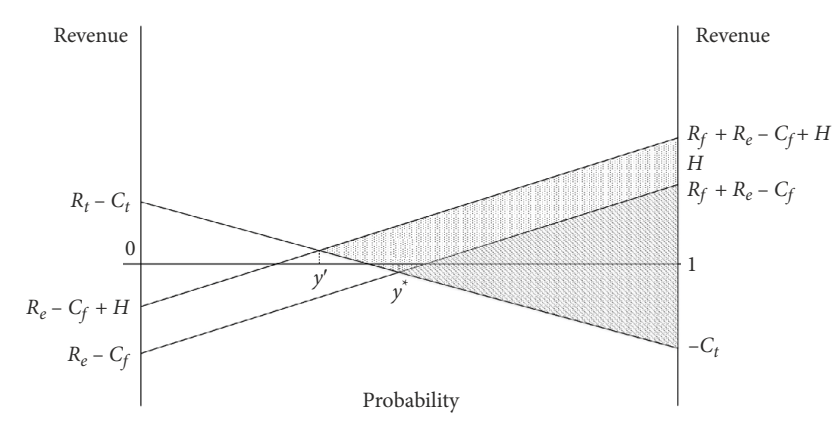

Figure 2. Developers' revenue

If the probability indicates the subsidy effect, it can be concluded that the DHS can improve the effect of $\delta y$ (Eqn (8)):

$$
\delta y=y^{*}-y^{\prime}=\frac{H}{R_{f}+R_{t}} .
$$

Similarly, customers' revenue is analyzed according to Table 1; developers have a probability of $x^{*}$ (Eqn (9)), and customers have the same revenue from $\mathrm{PH}$ and $\mathrm{CH}$. If developers have a probability larger than $x^{*}$, customers will choose to buy PH (see Appendix 1.1).

$$
x^{*}=\frac{R_{c}-C_{c}}{R_{u}-C_{u}+R_{c}-C_{c}} .
$$

If the government provides subsidy $\mathrm{F}$ for customers, then customers will obtain extra $\mathrm{F}$ when buying $\mathrm{PH}$, developers have a probability of $x^{\prime}$ (Eqn (10)), and customers have the same revenue from $\mathrm{PH}$ and $\mathrm{CH}$. If developers have a probability larger than $x^{\prime}$, customers will choose to buy PH (see Appendix 1.1).

$$
x^{\prime}=\frac{R_{c}-C_{c}}{R_{u}-C_{u}+R_{c}-C_{c}+F}<x^{*} .
$$

Figure 3 shows that $x^{\prime}<x^{*}$, which means that customers choose $\mathrm{PH}$ under the condition that developers have a low probability of choosing $\mathrm{PH}$. If the probability indicates the subsidy effect, then it can be seen that the CHS can improve the effect of $\delta x$ (Eqn (11)):

$$
\delta x=x^{*}-x^{\prime}=\frac{\left(R_{c}-C_{c}\right) F}{\left(R_{u}-C_{u}+R_{c}-C_{c}\right)\left(R_{u}-C_{u}+R_{c}-C_{c}+F\right)} .
$$

From the aforementioned model analysis, it can be seen that both DHS and CHS can improve the development of $\mathrm{PH}$, but they have different effects, which will be analyzed together in Section 4.

\subsection{Replicator dynamics equation}

After revenue analysis, the replicator dynamics equation should then be analyzed to determine how the subsidy effect changes over time.

In this part, DHS and CHS are both considered in the payment matrix in Table 2.

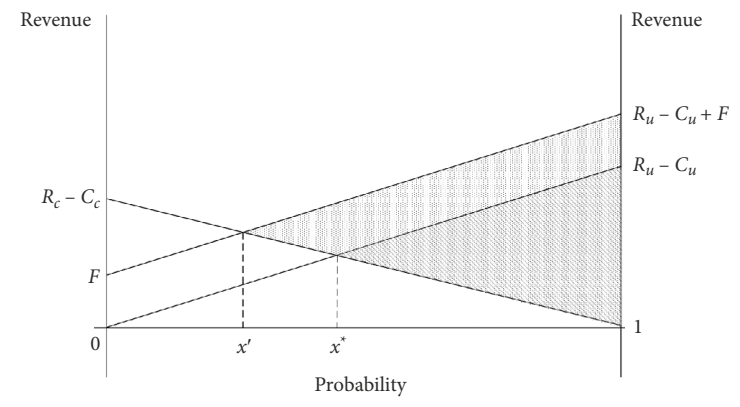

Figure 3. Customers' revenue

Table 2. Payment matrix between developers and customers with subsidies

\begin{tabular}{|c|l|l|}
\hline \multirow{2}{*}{ Developer } & \multicolumn{2}{|c|}{ Customer } \\
\cline { 2 - 3 } & \multicolumn{1}{|c|}{$\mathrm{PH}$} & $\mathrm{CH}$ \\
\hline $\mathrm{PH}$ & $\left(R_{f}+R_{e}-C_{f}+H, R_{u}-C_{u}+F\right)$ & $\left(R_{e}-C_{f}+H, 0\right)$ \\
\hline $\mathrm{CH}$ & $\left(-C_{t}, 0\right)$ & $\left(R_{t}-C_{t}, R_{c}-C_{c}\right)$ \\
\hline
\end{tabular}

Continuing to suppose that the probability that developers will develop PH is $\boldsymbol{x}$, and the probability that developers will develop $\mathrm{CH}$ is $1-x$, the probability that customers will buy $\mathrm{PH}$ is $y$, and the probability that customers will buy $\mathrm{CH}$ it is $1-y$.

Then, according to Table 2, the developers' revenue from developing $\mathrm{PH}$ is shown in Eqn (12):

$$
\begin{aligned}
& U_{11}=y\left(R_{f}+R_{e}-C_{f}+H\right)+(1-y)\left(R_{e}-C_{f}+H\right)= \\
& y R_{f}-C_{f}+R_{e}+H .
\end{aligned}
$$

The developers' revenue from developing $\mathrm{CH}$ is shown in Eqn (13):

$$
U_{12}=y\left(-C_{t}\right)+(1-y)\left(R_{t}-C_{t}\right)=(1-y) R_{t}-C_{t} .
$$

The developers' expected revenue is shown in Eqn (14):

$$
E_{1}=x U_{11}+(1-x) U_{12} \text {. }
$$

Then, the developers' replicator dynamics equation is shown in Eqn (15):

$$
\begin{aligned}
& G(x)=\frac{d x}{d t}=x\left(U_{11}-E_{1}\right)=\mathrm{x}(1-\mathrm{x})\left(U_{11}-U_{12}\right)= \\
& x(1-x)\left[y\left(R_{f}+R_{t}\right)+R_{e}-R_{t}+C_{t}-C_{f}+H\right] .
\end{aligned}
$$

Let $G(x)=0$; then, the evolution is at a stable state, and the results are shown in Eqn (16):

$$
x_{1}^{*}=0, x_{2}^{*}=1 \text {, and } y^{*}=\frac{R_{t}-R_{e}+C_{f}-C_{t}-H}{R_{f}+R_{t}} \text {. }
$$

When $\boldsymbol{y}=\boldsymbol{y}^{*}, G(x) \equiv 0$ can be obtained, and the game is at a stable state regardless of any $\boldsymbol{x}$ values, which means that developers have a stable initial proportion if customers have a probability of $\boldsymbol{y}^{*}$ of choosing PH.

When $\boldsymbol{y}<\boldsymbol{y}^{*}, G^{\prime}(0)<0, G^{\prime}(1)>0$, and $x_{1}^{*}=0$ is the only ESS, which means that customers do not have a suf- 
ficiently high probability of buying $\mathrm{PH}$ to influence the market, and developers are not willing to develop PH. Then, developers will generally choose $\mathrm{CH}$.

When $y>y^{*}, G^{\prime}(0)>0, G^{\prime}(1)<0$, and $x_{2}^{*}=1$ is the only ESS, which means that customers have a sufficiently high probability of buying $\mathrm{PH}$ to influence the market, and developers are willing to buy $\mathrm{PH}$. Then, developers will generally choose $\mathrm{PH}$, and the game reaches Pareto optimality, which means that the strategies of choosing $\mathrm{PH}$ form an efficient reaction and social resources are allocated in the most economically efficient manner (Mariano \& Bilbao, 2009).

Similarly, according to Table 2, the customers' replicator dynamics equation is shown in Eqn (17) (see Appendix 1.2).

$$
\begin{aligned}
& K(y)=\frac{d y}{d t}=y\left(U_{21}-E_{2}\right)=y(1-y)\left(U_{21}-U_{22}\right)= \\
& y(1-y)\left[x\left(R_{u}-C_{u}+R_{c}-C_{c}+F\right)-R_{c}+C_{c}\right] .
\end{aligned}
$$

Let $K(y)=0$; then, the evolution is at a stable state, and the results are shown in Eqn (18):

$$
y_{1}^{*}=0, y_{2}^{*}=1 \text {, and } x^{*}=\frac{R_{c}-C_{c}}{R_{u}-C_{u}+R_{c}-C_{c}+F} .
$$

When $\boldsymbol{x}=\boldsymbol{x}^{*}, K(y) \equiv 0$ can be obtained, and the game is at a stable state regardless of any $y$ values, which means that customers have a stable initial proportion if the developers have a probability of $\boldsymbol{x}^{\star}$ to develop PH.

When $x<x^{*}, K^{\prime}(0)<0, K^{\prime}(1)>0$, and $y_{1}^{*}=0$ is the only ESS, which means that developers do not have a sufficiently high probability of developing $\mathrm{PH}$ to influence the market, and customers are not willing to buy $\mathrm{PH}$. Then, customers will generally choose $\mathrm{CH}$.

When $x>x^{*}, K^{\prime}(0)>0, K^{\prime}(1)<0$, and $y_{2}^{*}=1$ is the only ESS, which means that developers have a sufficiently high probability of developing $\mathrm{PH}$ to influence the market, and customers are willing to buy $\mathrm{PH}$. Then, customers will generally choose $\mathrm{PH}$, and the game reaches Pareto optimality.

Therefore, there are five equilibrium points in the evolutionary game model, i.e., $(0,0),(0,1),(1,0),(1,1)$, and $\left(x^{*}\right.$, $\left.y^{*}\right)$. Furthermore, according to differential equation stability theory and Jacobian matrix stability analysis (ResendisAntonio, 2013), $G(x)$ and $K(y)$ are nonlinear differential equations, and Jacobian matrix $J$ can be used to analyze the stability of those five points (see Appendix 1.3). Then, there are four scenarios in the evolution of the strategy between developers and customers. The arrows in Figure 4 represent the trend in choosing $\mathrm{PH}$ or $\mathrm{CH}$. The arrows pointing to 0 indicate choosing $\mathrm{CH}$, while the arrows pointing to 1 indicate choosing $\mathrm{PH}$.

When $R_{u}-C_{u}+F<0, R_{f}+R_{e}-C_{f}+C_{t}+H<0$, the evolutionary strategy analysis of the developers and customers receiving the government subsidy is shown in Figure 4a. Under this condition, the two stakeholders' revenues from choosing $\mathrm{PH}$ are smaller than those from choosing $\mathrm{CH}$. Then, the developers and customers tend to choose $\mathrm{CH}$, and $(0,0)$ is ESS.
When $R_{u}-C_{u}+F>0, R_{f}+R_{e}-C_{f}+C_{t}+H<0$, the evolutionary strategy analysis of developers and customers with the government subsidy is shown in Figure 4b. Under this condition, the customers' revenue from buying $\mathrm{PH}$ is larger than the revenue from buying $\mathrm{CH}$, but the developers' revenue from developing $\mathrm{PH}$ is smaller than that from developing $\mathrm{CH}$. Because developers prefer $\mathrm{CH}$, customers have few opportunities to buy $\mathrm{PH}$ and will ultimately choose $\mathrm{CH}$, and $(0,0)$ is ESS.

When $R_{u}-C_{u}+F<0, R_{f}+R_{e}-C_{f}+C_{t}+H>0$, the evolutionary strategy analysis of developers and customers receiving the government subsidy is shown in Figure 4c. Under this condition, the customers' revenue from buying $\mathrm{PH}$ is lower than the revenue from buying $\mathrm{CH}$, but the developers' revenue from developing $\mathrm{PH}$ is larger than that from developing $\mathrm{CH}$. Because customers prefer $\mathrm{CH}$, developers have no market to sell $\mathrm{PH}$ and will ultimately choose $\mathrm{CH}$, and $(0,0)$ is ESS.

When $R_{u}-C_{u}+F>0, R_{f}+R_{e}-C_{f}+C_{t}+H>0$, the evolutionary strategy analysis of developers and customers receiving the government subsidy is shown in Figure 4d. Under this condition, the two stakeholders' revenues from choosing $\mathrm{PH}$ are larger than the revenues from choosing $\mathrm{CH}$. There are two ESSs: $(0,0)$ and $(1,1)$, and $\left(x^{*}, y^{*}\right)$ is a key saddle point.

In conclusion, the evolutionary results in Figures $4 \mathrm{a}$, $4 \mathrm{~b}$ and $4 \mathrm{c}$ are all $(0,0)$, which means that if neither the developers nor the customers choose $\mathrm{PH}$, they will obviously both choose $\mathrm{CH}$, whereas if one of them chooses $\mathrm{PH}$, the other will ultimately choose $\mathrm{CH}$. Figure $4 \mathrm{~d}$ depends on the area in which the original state is located. If the original state is in the area of $A B C D$, then the developers and customers tend to choose $\mathrm{PH}$, which is Pareto optimal. Otherwise, if the original state is in the area of OADC, they will finally choose $\mathrm{CH}$. The current development of $\mathrm{PH}$ in China is still in the initial phase, and the game between developers and customers will last for a long time. During this time, both $\mathrm{PH}$ and $\mathrm{CH}$ will exist.

\subsection{Simulation}

To compare the influences of DHS and CHS, this paper simulates the trend of probability while the subsidies change via MATLAB R2018a. It is assumed that $R_{f}=5$, $R_{t}=4, R_{e}=2, C_{f}=3, C_{t}=2, R_{u}=4, C_{u}=3, R_{c}=3$, and $C_{c}=2$. Then, $H$ and $F$ will increase from 0 .

Originally, when $H$ and $F$ are both 0 , the government provides no subsidy. The probability that developers and customers are willing to choose $\mathrm{PH}$ is shown in Figure 5, where $x$ represents the probability for developers and $y$ represents the probability for customers. According to Jia (2013) and the situation for PH in China (MOHURD, 2020b, 2021), it is assumed that developers and customers have a probability of 0.5 and 0.2 of choosing $\mathrm{PH}$, respectively, at first. Then, both developers and customers gradually tend to choose $\mathrm{CH}$ because there is no subsidy to stimulate them. 

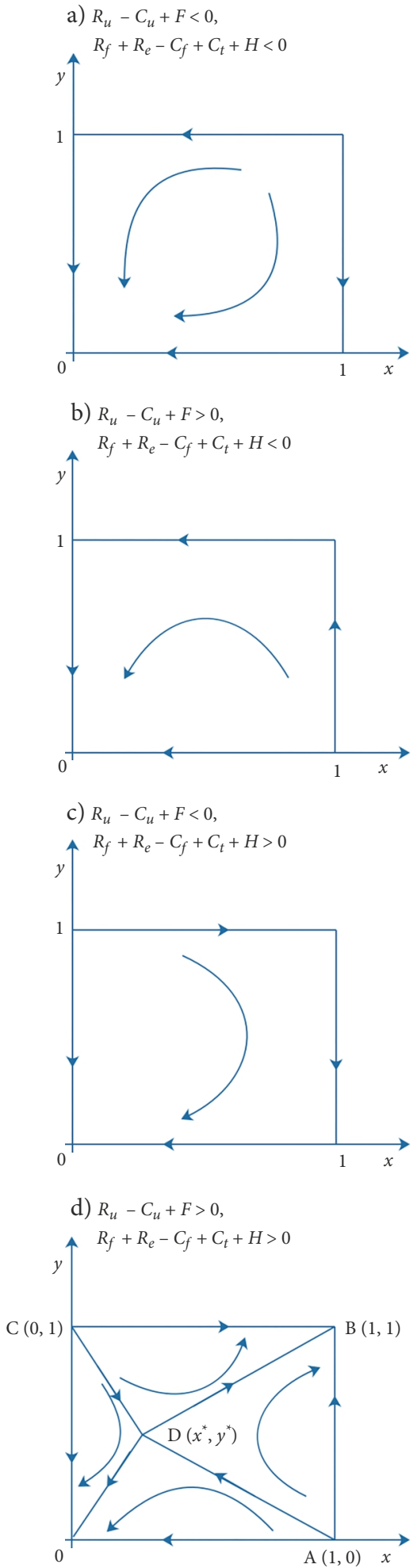

Figure 4. Combination strategy evolution diagram for developers and customers

Then, if the government gradually increases DHS $H$, the trend is as shown in Figure 6. When $H$ is small, the developers benefit from the subsidy indeed because the rate of decline becomes slow, but the subsidy is not so strong that the developers cannot receive enough benefits to develop $\mathrm{PH}$ and tend to choose $\mathrm{CH}$ gradually. Later, when $H$ is increasing, developers obtain enough benefits and have

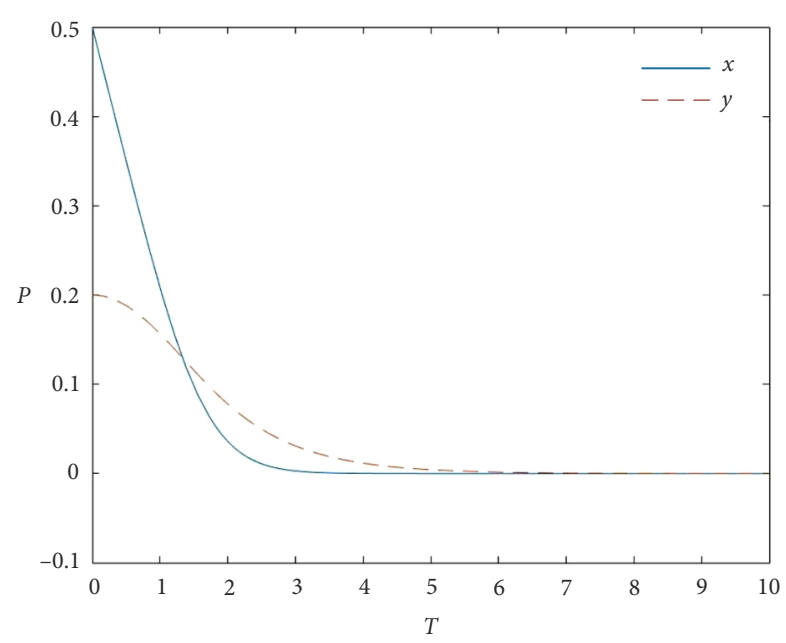

Figure 5. Probability trends for developers and customers $(H=0, F=0)$

a stronger willingness to develop $\mathrm{PH}$. With increasing $\mathrm{PH}$, customers will also prefer $\mathrm{PH}$.

If the government gradually increases the CHS F, the trend is as shown in Figure 7. When $F$ is small, customers benefit from the subsidy, and the probability increases slightly in the beginning, but the subsidy is not so strong that customers cannot receive enough benefits to buy $\mathrm{PH}$ and tend to choose $\mathrm{CH}$ gradually. Later, when $F$ is increasing, customers obtain enough benefits and have a stronger willingness to buy $\mathrm{PH}$. In the meantime, the developers' probability of developing $\mathrm{PH}$ decreases at first because there is no subsidy, but after the subsidy is implemented, the developers tend to promote $\mathrm{PH}$ as the demand increases. Comparing Figure 6 and Figure 7, it can be seen that both DHS and CHS can promote $\mathrm{PH}$, but the CHS can increase the probability that developers and customers will choose $\mathrm{PH}$ more quickly than the DHS.

Figure 7 shows that developers always decrease the probability in the beginning, so there is a better solution: the government offers the subsidy to developers first until the probability that they choose $\mathrm{PH}$ increases and then offers it to customers to increase this probability quickly. In fact, according to the S-type curve of the development of a city, developers are initially encouraged to develop more buildings to ease housing issues; after a period of housing shortage, customers are encouraged to promote the development of the housing market.

To verify the robustness of the model and the assumptions, another set of data are used to simulate the trends. It is assumed that $R_{f}=6, R_{t}=3, R_{e}=1, C_{f}=4, C_{t}=3, R_{u}=$ 5, $C_{u}=4, R_{c}=4$, and $C_{c}=3$. Then, $H$ and $F$ will increase from 0 . The detailed results can be seen in Figures 8, 9 and 10 . It can be seen that when $H / F$ is increasing, the developers/customers indeed benefit from the subsidy because the rate of decline slows and they gradually develop a stronger willingness to develop $\mathrm{PH}$. With increasing $\mathrm{PH}$, customers/developers will also prefer $\mathrm{PH}$. The figures show that the trends are similar to those for the first set of data, which means the simulation is robust. 
a) $H=1, F=0$

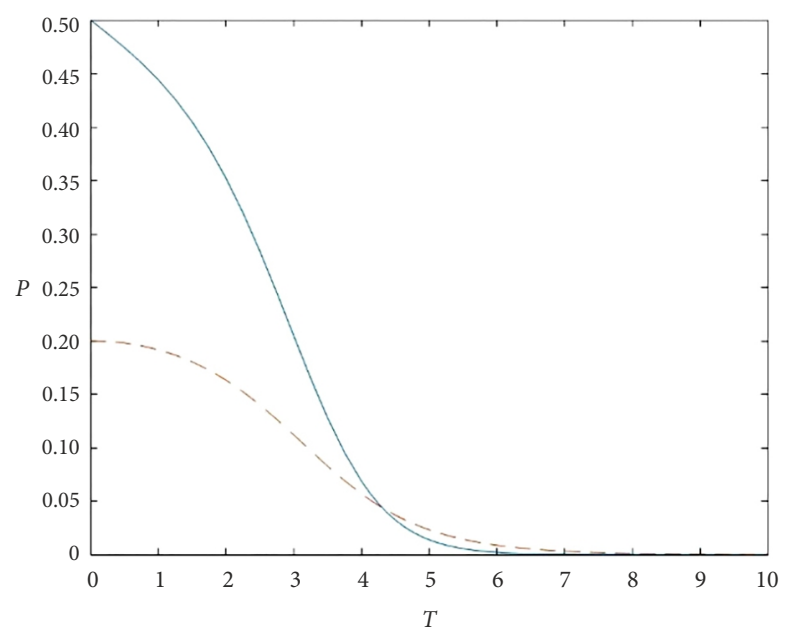

b) $H=3, F=0$

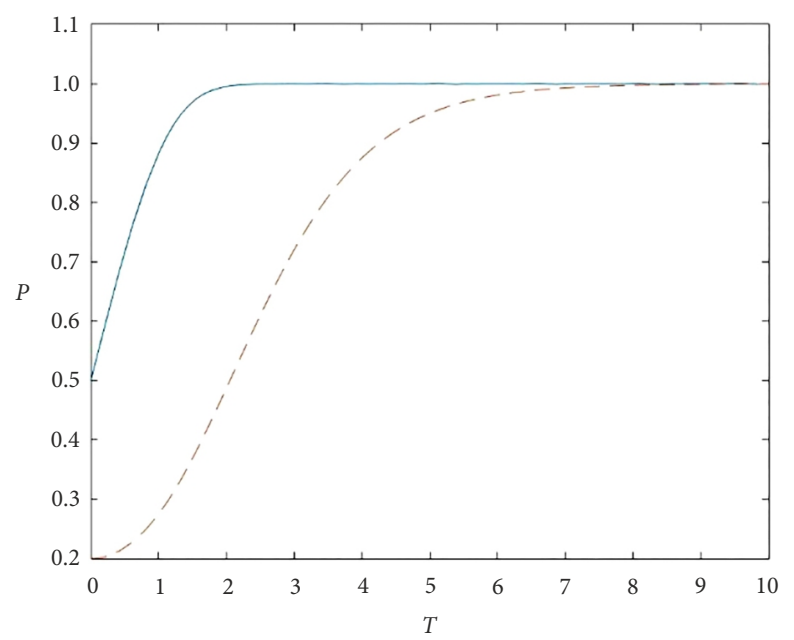

c) $H=5, F=0$

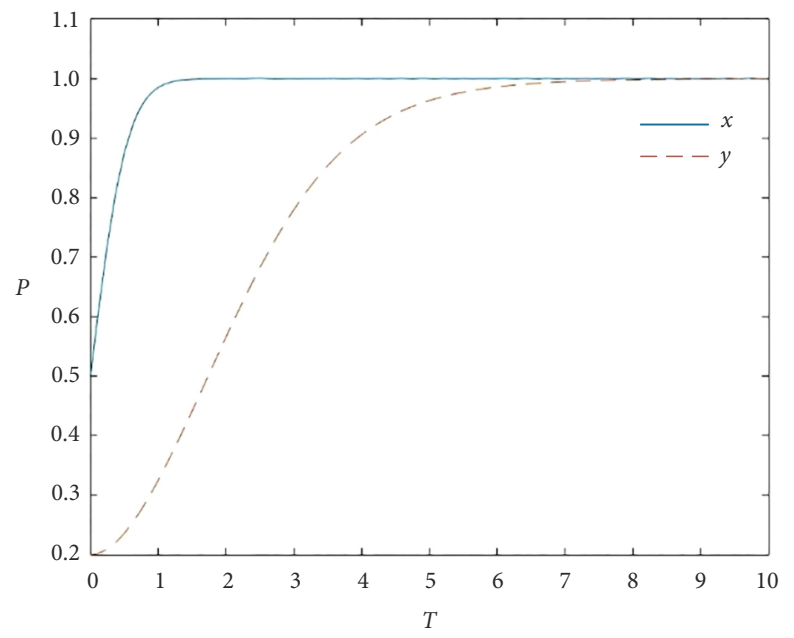

Figure 6. Probability trends for developers and customers $(H=1, H=3, H=5)$ a) $H=0, F=1$

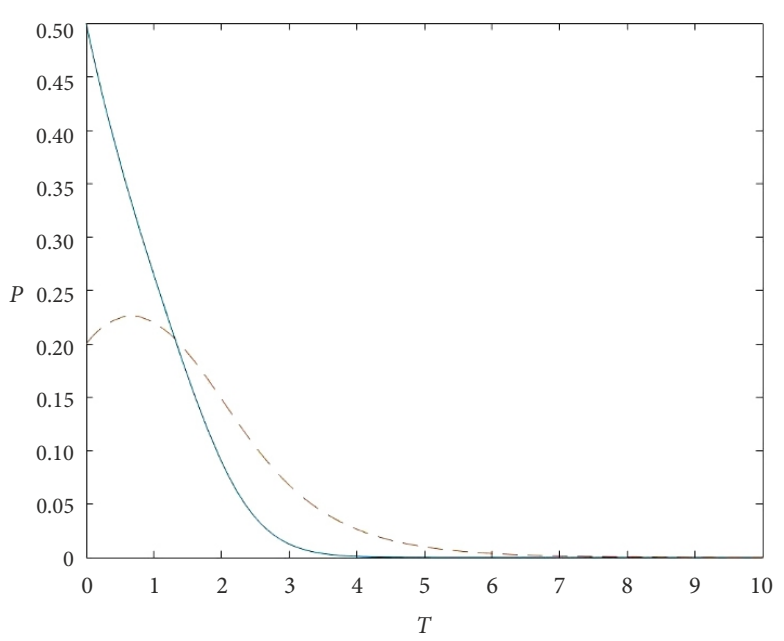

b) $H=0, F=3$

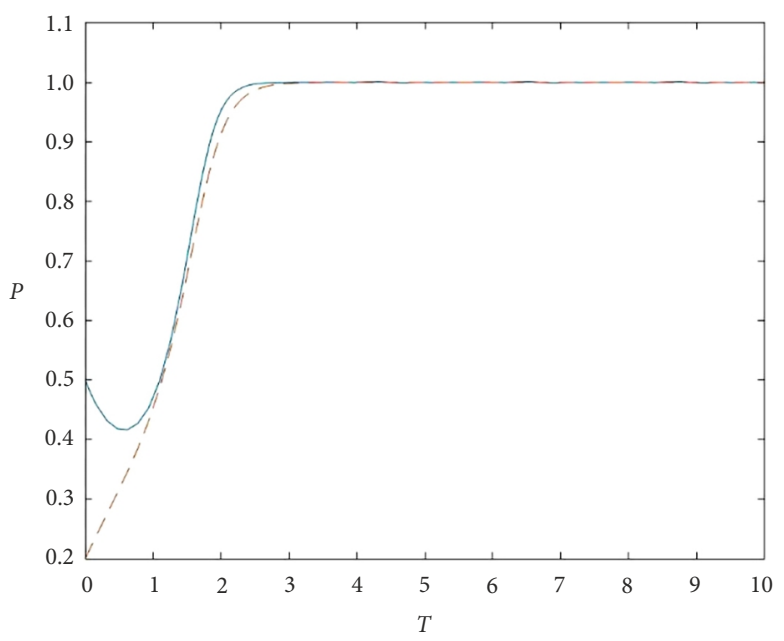

c) $H=0, F=5$

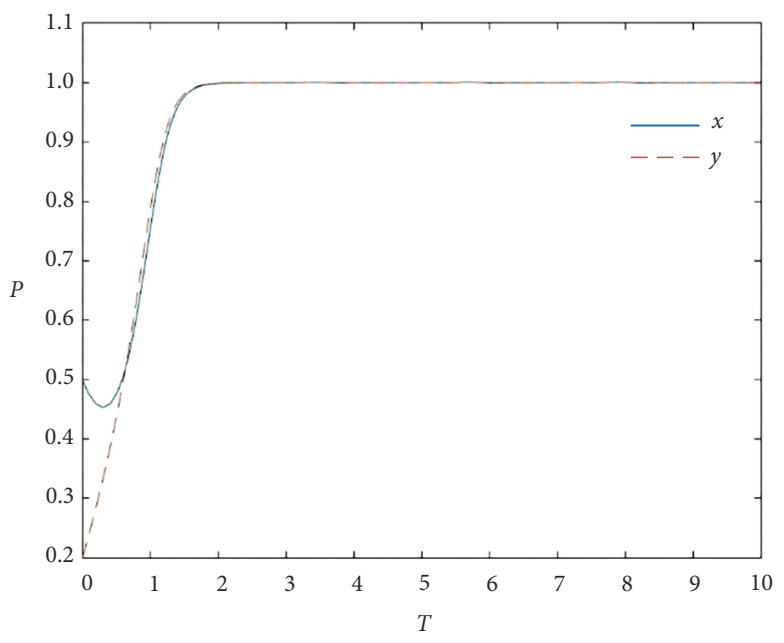

Figure 7. Probability trends for developers and customers $(F=1, F=3, F=5)$ 


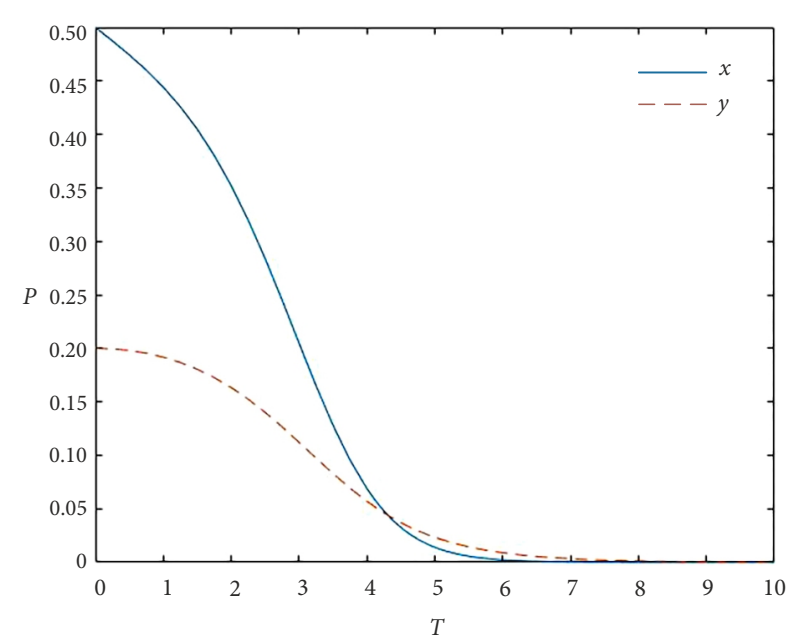

Figure 8. Probability trends for developers and customers with another data set $(H=0, F=0)$

\section{Results and empirical analysis}

\subsection{The scope of subsidies}

Figure 4 shows that $(0,0)$ and $(1,1)$ are the ESS, but only the scenario in Figure $4 \mathrm{~d}$ is likely to tend to $(1,1)$, which depends on which area point $D\left(x^{*}, y^{*}\right)$ is in. If $x^{*}$ or $y^{*}$ is smaller and point $D$ is closer to $(0,0)$, which means that the area of $\mathrm{ABCD}$ is larger, then there will be more points in the area of $\mathrm{ABCD}$, and developers and customers have a larger probability of choosing $\mathrm{PH}$ in the end. Thus, it is assumed that the area of $A B C D$ is the general probability of choosing $\mathrm{PH}$ by these two stakeholders. Then, the area of $\mathrm{ABCD}$ is shown in Eqn (19):

$$
\begin{aligned}
& S_{A B C D}=\frac{1}{2}\left(2-x^{*}-y^{*}\right)=\frac{1}{2}\left(2-\frac{R_{c}-C_{c}}{R_{u}+R_{c}-C_{c}-C_{u}+F}-\right. \\
& \left.\frac{R_{t}-R_{e}+C_{f}-C_{t}-H}{R_{f}+R_{t}}\right) .
\end{aligned}
$$

Furthermore, $\delta y$ in Eqn (8) and $\delta x$ in Eqn (11) are similar to the area change of $\mathrm{ABCD}$ (the partial derivatives of $H$ and $F$ ); therefore, the area changes with $H$ and $F$ will be discussed together.

Proposition 1. With increasing subsidies offered by the government, the area of $\mathrm{ABCD}$ will increase (Figure 11). Therefore, the government should play an effective role in energizing the market, and housing subsidies should be efficient (see Appendix 2.1).

Proposition 2. The rates at which area ABCD increases are different: as the rate of increase decreases, the area will reach an upper limit as $F$ increases, while the area of $\mathrm{ABCD}$ will always increase at a stable rate until the probability reaches 1 as $H$ increases (Figure 12).

The increase rate of the promotion depends on the CHS, costs and benefits. DHS affects only the increase in the promotion of $\mathrm{PH}$ instead of the increase rate. The costs and benefits are up to the developers and customers. The government can only control the subsidy, so the govern-

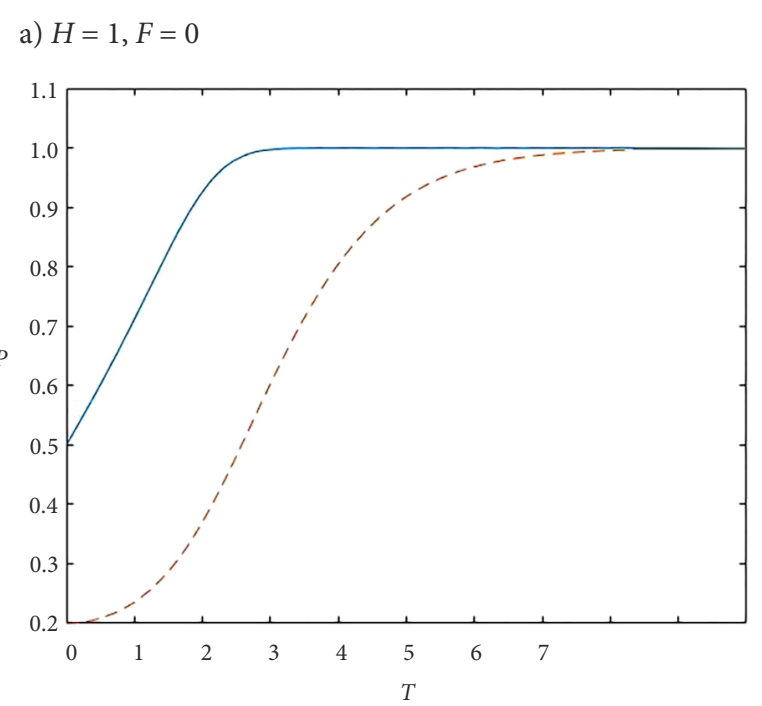

b) $H=3, F=0$

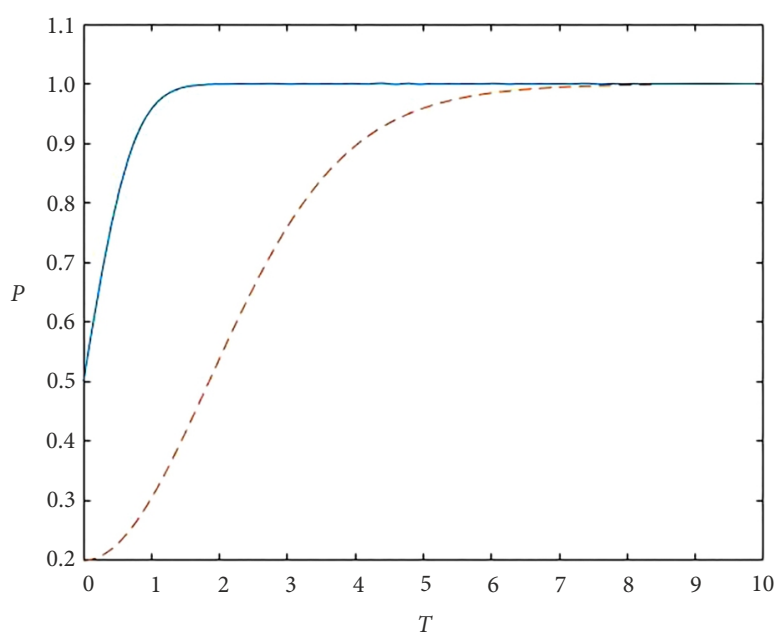

c) $H=5, F=0$

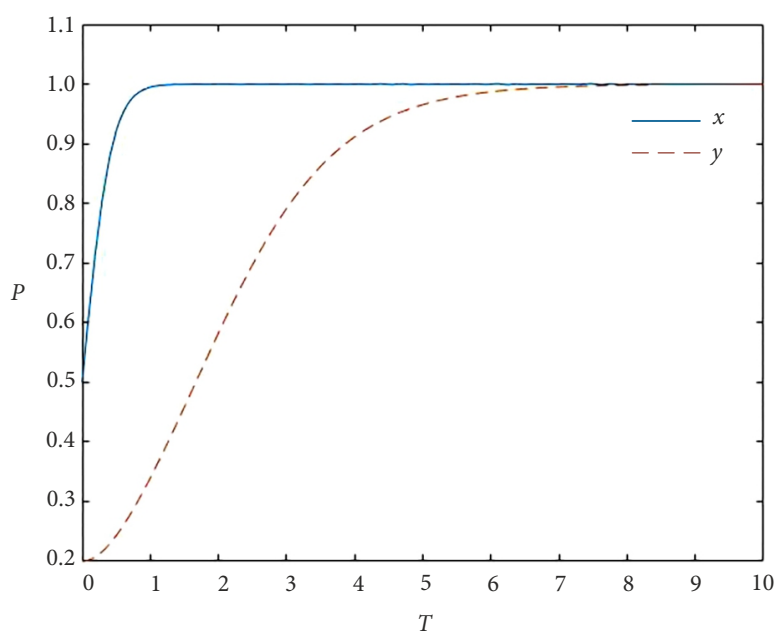

Figure 9. Probability trends for developers and customers with another data set $(H=1, H=3, H=5)$

ment should pay more attention to the CHS. Customers' demand can affect the market and developers' decisions. In this aspect, CHS is more important than DHS (see Appendix 2.2). 
a) $H=0, F=1$

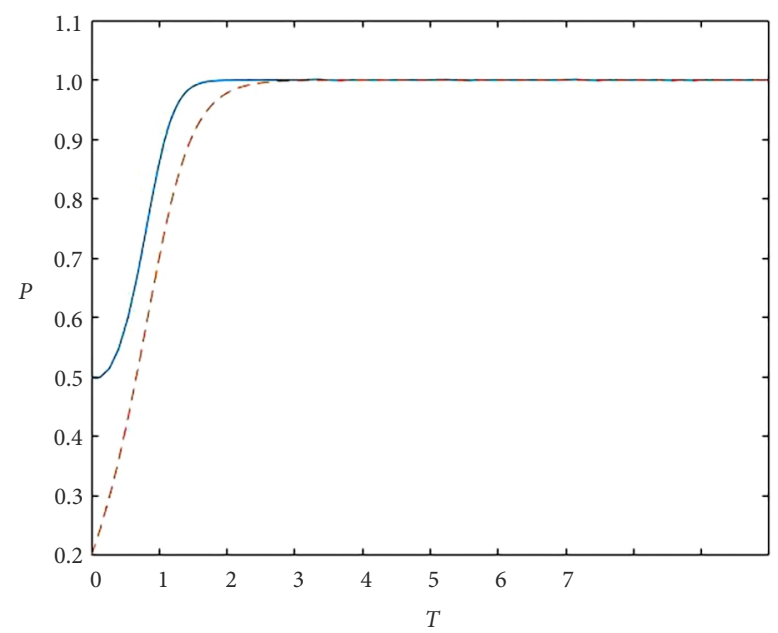

b) $H=0, F=3$

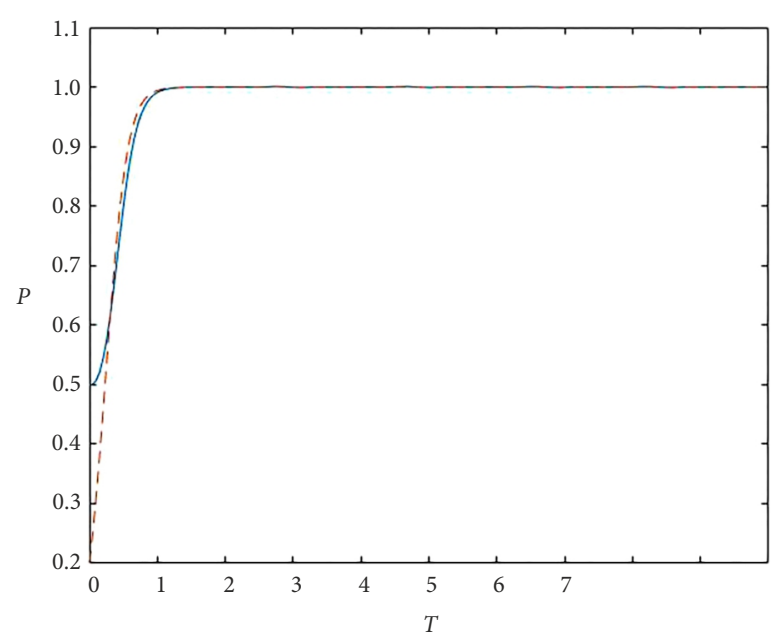

c) $H=0, F=5$

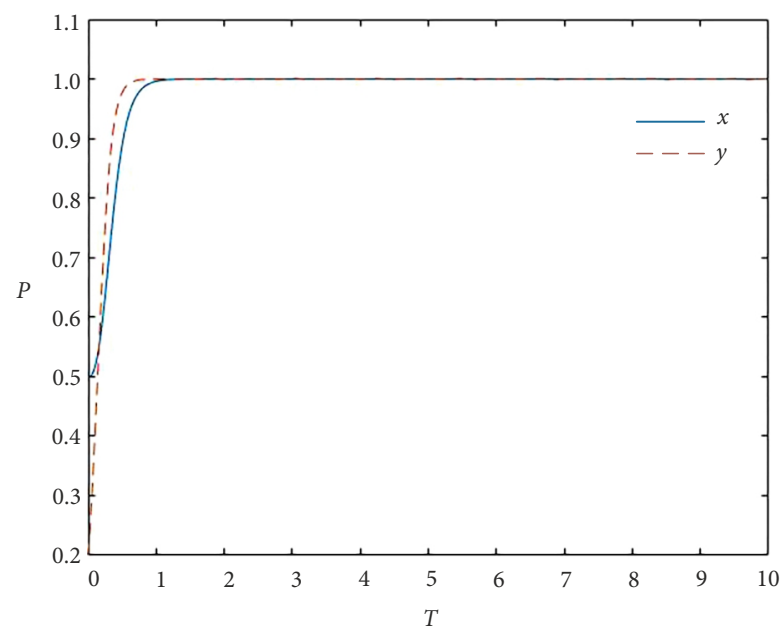

Figure 10. Probability trends for developers and customers with another data set $(F=1, F=3, F=5)$

Proposition 3. CHS can be large enough, and DHS should not be larger than the difference between the incremental benefit and incremental cost. The scope of subsidies $H$ and $F$ should satisfy the following inequalities:

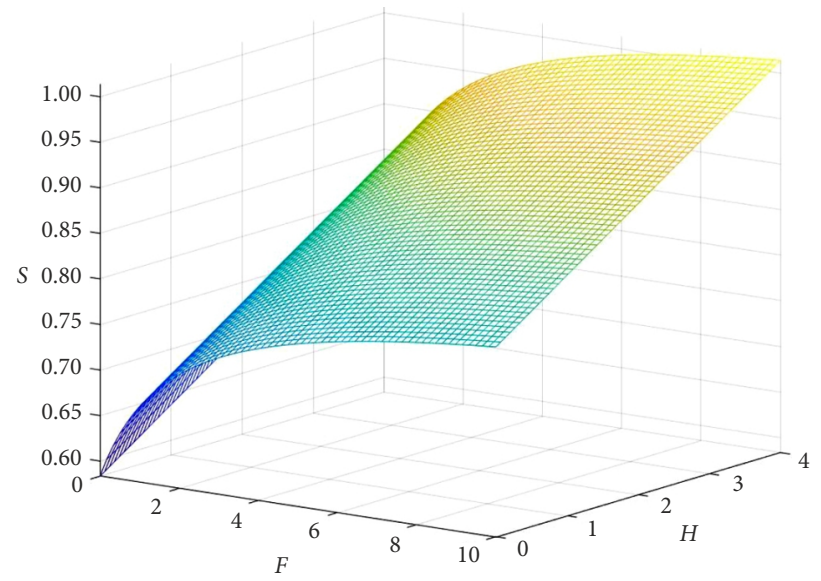

Figure 11. The area of ABCD

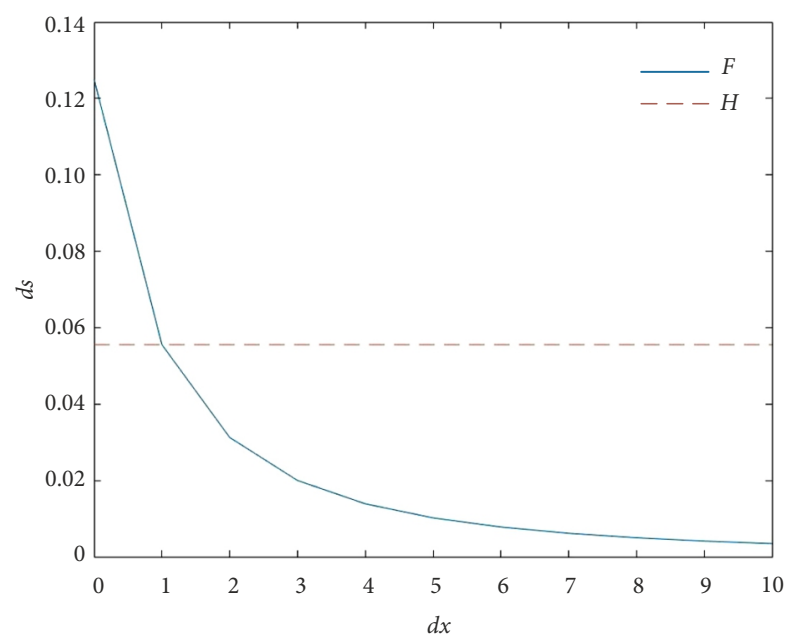

Figure 12. The rate of change in area ABCD

$$
\begin{aligned}
& C_{f}-C_{t} \leq H \leq R_{t}-R_{e}-C_{t}+C_{f} ; \\
& F \geq C_{u}-C_{c} .
\end{aligned}
$$

Therefore, if the subsidy is not strong, the government will provide it to customers because it can increase their probability of choosing $\mathrm{PH}$ quickly. If the subsidy is very strong, the government should provide it to developers because too strong a subsidy for customers will not increase the probability of choosing $\mathrm{PH}$, which causes waste in the subsidy, but the DHS can always increase the probability of choosing $\mathrm{PH}$. In fact, if the subsidy is not so strong that the developers cannot obtain enough profits and cannot even compensate for the incremental costs, the probability of developers choosing $\mathrm{PH}$ increases more slowly than the probability of customers choosing $\mathrm{PH}$ because the customers can benefit a great deal from a small subsidy and have a strong willingness to buy $\mathrm{PH}$. If the subsidy is strong enough to motivate developers, developers have a high probability of developing $\mathrm{PH}$, and prices will decrease enough to stimulate customers (see Appendix 2.3).

Proposition 4. The government should consider two situations to offer developers a subsidy: 


$$
\begin{aligned}
& \text { If } \sqrt{\left(R_{f}+R_{t}\right)\left(R_{c}-C_{c}\right)}+C_{c}+C_{u}-R_{c}-R_{u}>C_{f}-C_{t}, \\
& H>\sqrt{\left(R_{f}+R_{t}\right)\left(R_{c}-C_{c}\right)}+C_{c}+C_{u}-R_{c}-R_{u} ; \\
& \text { If } \sqrt{\left(R_{f}+R_{t}\right)\left(R_{c}-C_{c}\right)}+C_{c}+C_{u}-R_{c}-R_{u}<C_{f}-C_{t}, \\
& H>C_{f}-C_{t} .
\end{aligned}
$$

The government should offer customers subsidies smaller than $\sqrt{\left(R_{f}+R_{t}\right)\left(R_{c}-C_{c}\right)}+C_{c}+C_{u}-R_{c}-R_{u}$.

The subsidy scopes are analyzed through the model, and it is reasonable for the government to offer subsidies within the limits. The scopes depend on the costs and benefits of $\mathrm{PH}$ and $\mathrm{CH}$. Government subsidies should be based on the market, so the government should focus on the whole industry to decide the subsidy scope and investigate the costs and benefits for the two stakeholders (see Appendix 2.4).

\subsection{Time to stop the subsidies}

Proposition 5. If the developers and customers reach a probability of choosing $\mathrm{PH}$ of $x^{*}$ and $y^{*}$, respectively, it is reasonable for the government to stop the subsidies. The end time of the subsidies is related to $H$ and $F$.

Here, the probability $x$ and $y$ can be seen as the proportion of developers and customers who are willing to choose $\mathrm{PH}$. When the developers and customers who choose $\mathrm{PH}$ account for $x^{*}$ and $y^{*}$, respectively, the government no longer needs to offer subsidies, and increasingly more developers and customers are willing to choose $\mathrm{PH}$ actively by the market mechanism with a certain speed.

The government should confirm the subsidy scopes and amounts based on costs and benefits in the market and then decide when to stop the subsidies according to the subsidy amount and the market. Now, $\mathrm{PH}$ and $\mathrm{CH}$ will coexist for a long time. The end time can relieve the government's financial burden, and developers and customers will actively choose PH (see Appendix 2.5).

\subsection{Numerical example}

There are two similar buildings for a pilot project: one is cast-in-site building $\mathrm{A}$, and the other is prefabricated building $B$, which used precast exterior wall panels, precast composite slabs and precast stairs. Both A and B are frame structures and have 15 floors, one of which is underground. Both buildings have an area of approximately 7000 square meters.

The costs of the two kinds of buildings based on the project cost information are shown in Table 3. Based on the investigation, BEPAS and BEHIAS theory (International Organization for Standardization [ISO], 2006; Li et al., 2015), the environmental benefits are shown in Table 4 (Cao, 2012). It is difficult to identify social benefits, so the AHP and expert surveys were used to calculate the weights of all the benefits, and then the social benefits could be calculated. The customers' costs are the prices of $\mathrm{PH} / \mathrm{CH}$, which can be considered to be the developers' economic benefits. It is assumed that the developer's average yield rate is $20 \%$ (Jiang et al., 2013), which means $C_{c}=R_{t}=(1+20 \%) C_{t}$ and $C_{u}=R_{f}=(1+20 \%) C_{f}$. The customers' benefits are based on their resulting emotions and satisfaction. Based on the investigation and satisfaction theory (Mohit et al., 2010; Ukoha \& Beamish, 1997), customers' net benefits are shown in Table 5 according to the AHP and the expert surveys. A total of 24 professionals in the field of $\mathrm{PH}$ and 24 professionals in the field of $\mathrm{CH}$ were surveyed to identify the weights of the benefits of $\mathrm{PH}$ and $\mathrm{CH}$, respectively (see Appendix 3 ).

Table 3. Costs of the two kinds of buildings

\begin{tabular}{|l|c|c|}
\hline \multicolumn{1}{|c|}{ Costs $\left(\mathrm{yuan} / \mathrm{m}^{2}\right)$} & $\mathrm{A}\left(C_{t}\right)$ & $\mathrm{B}\left(C_{f}\right)$ \\
\hline Design & 15 & 17 \\
\hline Construction and installation & 1732 & 1863 \\
\hline Operation (property management) & 2.2 & 1.7 \\
\hline Maintenance & 14.122 & 4.051 \\
\hline Scrap & 1.583 & 3.972 \\
\hline Total & 1764.905 & 1889.723 \\
\hline
\end{tabular}

Table 4. Developer's benefits for the two kinds of buildings

\begin{tabular}{|l|c|c|}
\hline \multicolumn{1}{|c|}{ Developer's benefit $\left(\mathrm{yuan} / \mathrm{m}^{2}\right)$} & $\mathrm{A}$ & $\mathrm{B}$ \\
\hline Resource consumption & -6.31 & -4.84 \\
\hline Ecological destruction & -61.99 & -59.84 \\
\hline Health damage & -11.46 & -10.70 \\
\hline Energy consumption & -24.76 & -13.53 \\
\hline Society & 281.977 & 309.187 \\
\hline Total & 177.457 & 220.277 \\
\hline$R_{e}=\mathrm{B}-\mathrm{A}$ & \multicolumn{2}{|c|}{42.82} \\
\hline
\end{tabular}

Table 5. Customers' net benefits for the two kinds of buildings

\begin{tabular}{|l|c|c|}
\hline \multicolumn{1}{|c|}{ Net benefits $\left(\right.$ yuan $\left./ \mathrm{m}^{2}\right)$} & $\mathrm{A}\left(R_{c}-C_{c}\right)$ & $\mathrm{B}\left(R_{u}-C_{u}\right)$ \\
\hline Benefit - Cost & 42.134 & 46.200 \\
\hline
\end{tabular}

Then, the ranges of $H$ and $F$ are calculated as Eqns (24) and (25):

$$
\begin{aligned}
& R_{t}-R_{e}-C_{t}+C_{f}=2199.88 \text { yuan } / \mathrm{m}^{2} ; \\
& \sqrt{\left(R_{f}+R_{t}\right)\left(R_{c}-C_{c}\right)}+C_{c}+C_{u}-R_{c}-R_{u}= \\
& 341.53 \frac{\text { yuan }}{\mathrm{m}^{2}} .
\end{aligned}
$$

Then, $341.53 \leq H \leq 2199.79,149.78 \leq F \leq 341.53$, which means that the government should offer a DHS of approximately $341.53-2199.79$ yuan $/ \mathrm{m}^{2}$ and a CHS of approximately $149.78-341.53$ yuan $/ \mathrm{m}^{2}$.

This is simply a numerical example to show how to confirm the PH subsidy using the subsidy game model. The government should focus on the whole industry to decide the subsidy scope and end time after the amount is confirmed. 


\section{Discussion}

The aforementioned analysis shows that subsidies are a way to decrease costs. Recent developments still face the barrier of higher costs. There are many factors that increase the costs of PH. Some researchers have found that the costs of materials and machines increase most and that precast components cost most in the view of lifecycle cost analysis (Zhang et al., 2014a; Lu \& Yuan, 2013). Other researchers found that technology, management, supply chain and design cost most and are the main reasons for cost increases in view of the internal and external environment (Monty \& Barry, 2018).

$\mathrm{PH}$ is characterized as manufacturing. Component design and production are the main processes of prefabricated construction. The prefabrication ratio (PR) is an important index to show the combination of different components. In addition, as more components are produced and the supply chain improves, the average cost of components will decrease, which means that the production scale is another important index. The model with cost changes is further discussed.

\subsection{Relationships between costs and PR}

There are many precast components (e.g., precast slabs, precast stairs, precast balconies, precast walls, precast columns.) in China, and how they are combined will affect the costs at different levels. The Prefabricated Building Evaluation Standard (GB/T51129-2017) defines PR as the comprehensive proportion of prefabricated components used in the main structure, enclosure walls, internal partition walls, decoration and equipment pipelines above the outdoor floor of a single building (Standardization Administration of China [SAC], 2017). PR is an important index to show the industrial level. Prefabricated production is based on standardized design and component customization to improve building quality and productivity, so the PR can to some extent reflect the technology level of industrialization.

Few studies have analyzed the relationships between costs and PR because the influence of PR on costs is very complicated, and there are not enough data to support the analysis. For example, the same PR with different combinations of components may result in totally different costs. It is not easy to eliminate the interference of other factors (e.g., areas, equipment, floors.) in the model because each building is unique. Recent studies simulate and compare the relationships between costs and PR by controlling factors as much as possible. Lopez and Froese (2016) compared panelized and modular prefabricated houses and found that modular houses are more cost efficient; they also applied a modular method to panelized housing and found that the cost of panelized housing decreased. Hong et al. (2018) analyzed 8 buildings via regression analysis and found that the cost intensity and incremental cost intensity both have a positive correlation with the PR. Yao (2018) fit an inverse $U$ curve of the relationships between the incremental cost and PR and showed that the cost increased when the ratio was between $10-20 \%$, the cost increased stably when the ratio was between $20-40 \%$, the cost increased faster when the ratio was between $40-65 \%$, and the incremental cost decreased after the ratio was over $65 \%$. This study investigated all prefabricated public housing in Beijing and found that when the ratio was small or very large, the incremental cost increased slowly, while it increased quickly when the ratio was between 20 and $40 \%$.

The relationships between the cost and PR are still unclear, although it is obvious that prefabricated component production and application increase the costs. On the basis of the survey and literature review, it is assumed that $f(p)$ is the incremental cost function and $p$ is the PR; therefore, the cost of PH is shown in Eqn (26):

$$
C_{f}(p)=C_{t}+f(p)
$$

It is complicated to describe the function, so the 3 scenarios are discussed below:

(1) When development is at the initial stage, the market is not formed, and developers are exploring $\mathrm{PH}$. The PR is low because there is no high-level technology, and therefore, the production scale is not formed. At that stage, the incremental cost increases quickly as the ratio increases.

(2) When PH develops, the market becomes active, and an increasing number of developers are willing to choose $\mathrm{PH}$. However, the technology still does not break through. The technology level and $\mathrm{PR}$ are increasing with increasing experience, so there are more options for precast components, and cheaper ones can be applied. Although the cost is still higher than $\mathrm{CH}$, the production cost can be apportioned. A higher PR makes construction management more effective, and the cost increases slowly.

(3) When the market is formed and the advantages become significant, the technology breaks through and the PR increases. More experience and components can better control the costs. In this stage, the incremental cost will decrease as the ratio increases and finally reach a stable rate.

Therefore, the relationships between the cost and PR are given in Table 6.

According to Eqn (19) and Eqns (A2.1) and (A2.2) from Appendix 2.1, $f(p)$ has no impact on the change in $H$ and $F$. Then, the paper will discuss the impact of the PR change on the ABCD area (Eqns (27) and (28)):

$$
\begin{aligned}
& \frac{\partial S_{A B C D}}{\partial p}=-\frac{1}{2} \times \frac{f^{\prime}(p)}{R_{f}+R_{t}} ; \\
& \frac{\partial^{2} S_{A B C D}}{\partial p^{2}}=-\frac{1}{2} \times \frac{f^{\prime \prime}(p)}{R_{f}+R_{t}} .
\end{aligned}
$$

There are three scenarios in which the PR changes, so the area will change in 3 scenarios.

(1) $f^{\prime}(p)>0, f^{\prime \prime}(p)>0$.

In the primary stage of the development of $\mathrm{PH}$, the cost increases considerably. When the PR increases, 
Table 6. The relationships between the cost and PR in different scenarios

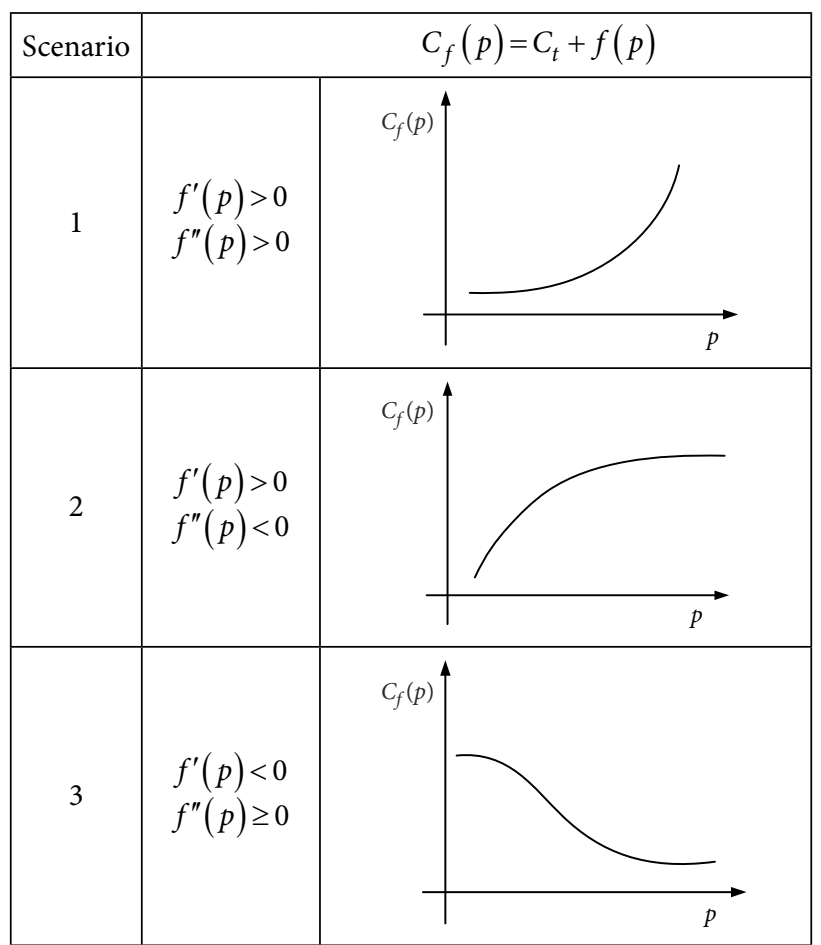

$\frac{\partial S_{A B C D}}{\partial p}<0$ and $\frac{\partial^{2} S_{A B C D}}{\partial p^{2}}<0$, which means that the area will decrease, especially when the ratio is very high, and the area will decrease quickly. The higher the ratio the developers are asked to build, the fewer developers will choose $\mathrm{PH}$. Therefore, developers are not willing to develop high-precast-ratio housing. During the initial period, the government should not focus on a high PR but rather on technology innovation and subsidies.

(2) $f^{\prime}(p)>0, f^{\prime \prime}(p)<0$.

During development, the cost still increases, but $\frac{\partial S_{A B C D}}{\partial p}<0$ and $\frac{\partial^{2} S_{A B C D}}{\partial p^{2}}>0$, which means that the area will still decrease, but the rate of decrease will also decrease until the area is close to $1-\frac{1}{2} \times \frac{R_{c}-C_{c}}{R_{u}+R_{c}-C_{c}-C_{u}+F}$. As technology develops, some developers may consider highratio buildings, but a high ratio still affects their enthusiasm. The government should support developers who try to develop high-ratio buildings.

(3) $f^{\prime}(p)<0, f^{\prime \prime}(p) \geq 0$.

When the market is formed and technology is developed, the cost will decrease. At this stage, $\frac{\partial S_{A B C D}}{\partial p}>0$ and $\frac{\partial^{2} S_{A B C D}}{\partial p^{2}} \leq 0$, which means that the area will increase as the ratio increases until the area reaches stability. Therefore, an increasing number of developers are encouraged to build high-ratio housing, and the government only needs to support developers that start PH with a low PR.

\subsection{Relationships between the cost and production scale}

The production scale is based on the number of precast components. If the scale is not formed and few components can be produced, the cost is very high. Then, the developers are not willing and are unable to expand the scale as a result of the high cost. Therefore, there will be a vicious circle, and the government should break the circle from the outside to help developers decrease costs (Figure 13).

According to economies of scale, advanced technology and equipment can achieve mass production. Then, the cost of each component can be shared and decrease the total cost. Standardization and universalization can improve the quality, decrease the material consumption and improve technology. Industry chain integration can save the cost of management and workers to improve technology and competitiveness.

Recent research on the production scale is based on the use of regression and data envelopment analysis (DEA) models to analyze the input-output relationships (Shi \& Smyth, 2012; Shapiro, 1973). Luo (1991) confirmed the relationship between the cost and scale of a cement plant $\left(C=A e^{\mu} S^{b}\right)$ using ER and determined that 14 enterprises are DEA efficient using DEA.

$\mathrm{PH}$ has a similar manufacturing character, so it is assumed to be Eqn (29):

$$
C_{f}=A n^{a} E^{b}
$$

where $A$ is a constant, $E$ is the scale of the component factory, $b$ is the scale economy coefficient, and $n$ is the number of ancillary facilities. According to the scale economy, the cost will decrease as the scale increases, so $\frac{\partial C_{f}}{\partial E}<0$, $\frac{\partial^{2} C_{f}}{\partial E^{2}} \geq 0$ and $A b<0$.

According to the scale economy, the cost will decrease and then increase as the scale expands. Therefore, there is the lowest cost $C_{f}^{*}$ and optimal scale $E^{*}$.

According to Eqn (19), the area of $A B C D$ is shown as Eqn (30):

$$
\begin{aligned}
& S_{A B C D}=\frac{1}{2}\left(2-x^{*}-y^{*}\right)=\frac{1}{2}\left(2-\frac{R_{c}-C_{c}}{R_{u}+R_{c}-C_{c}-C_{u}+F}-\right. \\
& \left.\frac{R_{t}-R_{e}+A n^{a} E^{b}-C_{t}-H}{R_{f}+R_{t}}\right) .
\end{aligned}
$$

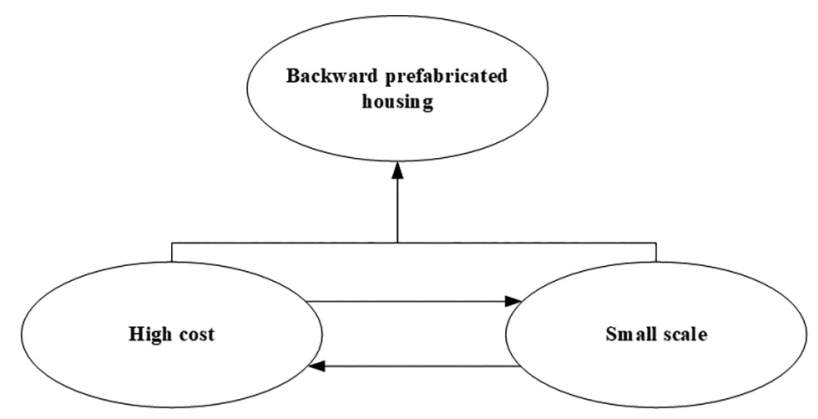

Figure 13. The vicious circle of the cost and scale 
According to Eqn (19) and Eqns (A2.1) and (A2.2) from Appendix 2.1, $E$ has no impact on the change in $H$ and $F$. Then, the paper will discuss the impact of the scale change on the area $\mathrm{ABCD}$ (Eqns (31) and (32)):

$$
\begin{aligned}
& \frac{\partial S_{A B C D}}{\partial E}=-\frac{1}{2} \times \frac{A b n^{a} E^{b-1}}{R_{f}+R_{t}}>0 ; \\
& \frac{\partial^{2} S_{A B C D}}{\partial E^{2}}=-\frac{1}{2} \times \frac{A b(b-1) n^{a} E^{b-2}}{R_{f}+R_{t}} \leq 0 .
\end{aligned}
$$

The equations show that the area will increase as the scale increases, but the area will not increase all the time and reach a maximum $S_{A B C D}^{*}$ because there is an optimal scale $E^{*}$. It will become a diseconomy of scale if the scale is larger than $E^{*}$. Therefore, the government should support component factories with complete facilities and factories, and factories should improve their production capacity and standardized level; then, developers prefer to cooperate with them.

\section{Conclusions}

The game model of government subsidies in this study reinforces our understanding of the breadth and depth of hidden concerns in terms of the objects, scopes, amounts, boundaries and end times of these subsidies and the influences on developers' and customers' transactions and decisions. This research contributes to the development of PH and can help the government quantitatively confirm the scopes, boundaries, amounts and end times to develop reasonable incentive policies based on this game model. The paper also analyzes the influences of costs on subsidies. This paper develops the following findings and recommendations that can help stimulate developers and customers to choose $\mathrm{PH}$ and energize the market in an efficient way:

- Subsidies have a positive impact on promoting $\mathrm{PH}$, and the CHS is more impactful than the DHS. The DHS can lower housing prices, while the CHS can increase prices. The government should provide subsidies for both developers and customers, but customers are more likely to influence the market.

- The government should offer developers subsidies first during the early development stage to increase the supply. Then, when the market develops to a certain scale, the government should offer customer subsidies instead (refer to Propositions 1-2).

- The subsidies' scopes, boundaries and amounts are based on the costs and benefits of $\mathrm{PH}$ and $\mathrm{CH}$. The government should focus on the developers' and customers' costs and benefits of $\mathrm{PH}$ and $\mathrm{CH}$, which means that the government should completely understand the construction industry and housing market. To develop PH faster, the government should offer developers a larger subsidy amount to offsite costs and stimulate them to develop a large amount of $\mathrm{PH}$, while the government should offer customers a smaller subsidy amount because a smaller amount can stimulate more customers to buy PH. Combined with the second point, the government should offer developers a larger subsidy during the early development stage and then offer customers a smaller subsidy amount later (refer to Propositions 3-4).

- The government should focus on the two stakeholders' costs and benefits of $\mathrm{PH}$ and $\mathrm{CH}$ to confirm the end times. To optimize financial expenditures, the government cannot always provide subsidies. It should track the proportion of developers and customers who choose $\mathrm{PH}$ to decide the end times. The proportion represents the market scale, and when the proportion reaches a certain degree, the subsidy can be eliminated and the market will develop naturally (refer to Proposition 5).

- The government should pay more attention to facilities and support factories to improve their production scale. Moreover, the government should not always emphasize PR because a higher PR may not always improve the development of $\mathrm{PH}$ in different stages. Instead of focusing on a high PR, the government should turn its attention to technology innovation and subsidies during the initial period, and then support developers who try to develop high-ratio buildings as the technology develops and support developers who start PH with a low PR as the market is formed and the technology is developed (refer to the Discussion).

The findings provide theoretical insights into subsidies in the PH market and how to confirm reasonable subsidy decisions. The evolutionary game model in this paper indicates the dynamic decisions and trends in the development of $\mathrm{PH}$ and determines the scopes, boundaries, amounts and end times of the subsidies. It is easier for laypersons to understand the complex influences of subsidies on the development of $\mathrm{PH}$ by analyzing the relationships between developers and customers in their decision-making with governmental incentive support. This study can not only deliver an effective understanding of the decision-making process but also help the government make reasonable decisions to adjust developers' and customers' needs and concerns. The government plays an important role in developing PH; developers and customers play a meaningful role as integral parts of the community to promote the $\mathrm{PH}$ market. The government needs to understand the costs and benefits of the construction industry, make reasonable subsidy policies within the limits of financial expenditure and propel the market forward naturally and actively.

This study considered only the interactions between developers and customers, but it is also important for other stakeholders, such as component factories, to improve production capacity. The government should also consider incentive policies for other stakeholders. We anticipate that future research should consider more stakeholders and more specific subsidy types; moreover, the optimal combinations of different types of subsidies need to be 
analyzed for the government to make specific policies. The specific relationships between costs and the PR should be identified to be clearly understood.

\section{Acknowledgements}

This work was supported by the National Natural Science Foundation of China (No. 51868016 and No. 51778335). The authors also would like to thank the Beijing Public Housing Office and Mr. Guoquan Liu in China Vanke Co., Ltd. for their assistance in data and policy collection.

\section{References}

Beijing Municipal Commission of Housing and Urban-Rural Development. (2010). Interim preferential measures for the implementation of area awards for industrialized residential projects (in Chinese).

Beijing Municipal Commission of Housing and Urban-Rural Development. (2011). Interim preferential measures for the implementation of area awards for industrialized residential projects (in Chinese).

Cao, X. Y. (2012). Environmental impact assessment and comparative studies on industrialized house and traditional house construction. Tsinghua University (in Chinese).

Cao, X. Y., Li, X. D., Zhu, Y. M., \& Zhang, Z. H. (2015a). A comparative study of environmental performance between prefabricated and traditional residential buildings in China. Journal of Cleaner Production, 109, 131-143. https://doi.org/10.1016/j.jclepro.2015.04.120

Cao, X. Y., Li, Z. F., \& Liu, S. (2015b). Study on factors that inhibit the promotion of SI housing system in China. Energy and Buildings, 88, 384-394.

https://doi.org/10.1016/j.enbuild.2014.11.064

Casares, E. R., Ruiz-Galindo, L. A., \& García-Salazar, M. G. (2018). Transitional dynamics, externalities, optimal subsidy, and growth. Journal of Dynamics \& Games, 5(1), 41-59. https://doi.org/10.3934/jdg.2018005

Fan, R. G., \& Dong, L. L. (2018). The dynamic analysis and simulation of government subsidy strategies in low-carbon diffusion considering the behavior of heterogeneous agents. Energy Policy, 117, 252-262.

https://doi.org/10.1016/j.enpol.2017.12.003

Gu, S. Y., Zhang, P., \& Yang, J. Y. (2018). System dynamics model based on evolutionary game theory for quality supervision among construction stakeholders. Journal of Civil Engineering and Management, 24(4), 318-330.

https://doi.org/10.3846/jcem.2018.3068

Hassani, H., Sattar, M., Odulaja, A., \& Santoso, W. M. (2018). A statistical approach for a fuel subsidy mechanism. Energy Policy, 119, 666-673. https://doi.org/10.1016/j.enpol.2018.04.012

Hong, J. K., Shen, G. Q., Li, Z., Zhang, B., \& Zhang, W. (2018). Barriers to promoting prefabricated construction in China: A cost-benefit analysis. Journal of Cleaner Production, 172, 649-660. https://doi.org/10.1016/j.jclepro.2017.10.171

Hong, J., She, Y., Wang, S. Y., \& Marinova, D. (2019). Impact of psychological factors on energy-saving behavior: Moderating role of government subsidy policy. Journal of Cleaner Production, 232, 154-162.

https://doi.org/10.1016/j.jclepro.2019.05.321

Huang, S. J., \& Wu, Q. W. (2018). Dynamic subsidy method for congestion management in distribution networks. IEEE Transactions on Smart Grid, 9(3), 2140-2151.

https://doi.org/10.1109/TSG.2016.2607720
Shi, H., \& Smyth, R. (2012). Economies of scale in the Australian tourism industry. Applied Economics, 44(33), 4355-4367. https://doi.org/10.1080/00036846.2011.589819

International Organization for Standardization. (2006). Environmental management - Life cycle - Principles and framework (ISO Standard No. 14040:2006).

https://www.iso.org/standard/37456.html

Jia, E. L. (2013). The study of incentive mechanism on housing industrialization in our country: A perspective of evolutionary game theory [Master's thesis]. Business School, Sun Yat-Sen University, Guangdong, China (in Chinese).

Jia, F. L. (2016). The evaluation of housing subsidies and system reconstruction of the public housing [ $\mathrm{PhD}$ dissertation]. School of Mathematics and Statistics, Central China Normal University, Wuhan, China (in Chinese).

Jiang, S. S., Yang, G. S., \& Xu, X. (2013). Building green building subsidy model design based on the government benefits. Project Management Technology, 11(10), 67-71 (in Chinese).

Kemp, P. A. (2010). The role and design of income-related housing allowances. International Social Security Review, 53(3), 43-57. https://doi.org/10.1111/1468-246X.00077

Keser, C., \& van Winden, F. (2000). Conditional cooperation and voluntary contributions to public goods. Scandinavian Journal of Economics, 102(1), 23-39.

https://doi.org/10.1111/1467-9442.00182

Khanzadi, M., Eshtehardian, E., \& Chalekaee, A. (2016). A game theory approach for optimum strategy of the owner and contractor in delayed projects. Journal of Civil Engineering and Management, 22(8), 1066-1077.

https://doi.org/10.3846/13923730.2016.1210222

Li, X. J. (2020). Research on investment risk influence factors of prefabricated building projects. Journal of Civil Engineering and Management, 26(7), 599-613. https://doi.org/10.3846/jcem.2020.12917

Li, X. D., Su, S., Shi, J., \& Zhang, Z. H. (2015). An environmental impact assessment framework and index system for the preuse phase of buildings based on distance-to-target approach. Building and Environment, 85, 173-181.

https://doi.org/10.1016/j.buildenv.2014.11.035

Lopez, D., \& Froese, T. M. (2016). Analysis of costs and benefits of panelized and modular prefabricated homes. Procedia Engineering, 145, 1291-1297.

https://doi.org/10.1016/j.proeng.2016.04.166

Lu, W., \& Yuan, H. (2013). Investigating waste reduction potential in the upstream processes of offshore prefabrication construction. Renewable and Sustainable Energy Reviews, 28, 804-811. https://doi.org/10.1016/j.rser.2013.08.048

Luo, W. (1991). Theoretical and positive study on economy of scale [Master's thesis]. School of Economics and Management, Tsinghua University. Beijing, China (in Chinese).

Mariano, J., \& Bilbao, A. (2009). Pareto-optimal solutions in fuzzy multi-objective linear programming. Fuzzy Sets and Systems, 160, 2714-2721. https://doi.org/10.1016/j.fss.2008.12.005

Ministry of Housing and Urban-Rural Development of the People's Republic of China. (2020a). Overview of the development of prefabricated buildings in 2019 (in Chinese).

Ministry of Housing and Urban-Rural Development of the People's Republic of China. (2020b). Research on green development of prefabricated buildings (in Chinese).

Ministry of Housing and Urban-Rural Development of the People's Republic of China. (2021). Circular on the development of prefabricated buildings in China in 2020 (in Chinese).

Mohit, M. A., Ibrahim, M., \& Rashid, Y. R. (2010). Assessment of residential satisfaction in newly designed public low-cost housing in Kuala Lumpur, Malaysia. Habitat International, 34(1), 18-27. https://doi.org/10.1016/j.habitatint.2009.04.002 
Monty, S., \& Barry, C. (2018). Investigating the cost of offsite in Western Australia. International Journal of Housing Markets and Analysis, 12(1), 5-24.

Qian, Q. K., Chan, E. H. W., Visscher, H., \& Lehmann, S. (2015). Modeling the green building (GB) investment decisions of developers and end-users with transaction costs (TCs) considerations. Journal of Cleaner Production, 109(16), 315-325. https://doi.org/10.1016/j.jclepro.2015.04.066

Resendis-Antonio, O. (2013). Jacobian matrix. In W. Dubitzky, O. Wolkenhauer, K.-H. Cho, \& H. Yokota (Eds.), Encyclopedia of systems biology. Springer.

https://doi.org/10.1007/978-1-4419-9863-7_1367

Roca, C. P., Cuesta, J. A., \& Sánchez, A. (2009). Evolutionary game theory: temporal and spatial effects beyond replicator dynamics. Physics of Life Reviews, 6(4), 208-249.

https://doi.org/10.1016/j.plrev.2009.08.001

Shapiro, D. (1973). Economy of scale as a cost factor in the operation of school districts in Alberta. Canadian Journal of Economics, 6(1), 114-121. https://doi.org/10.2307/133867

Siqueira, K., \& Sandler, T. (2004). Collective goods, common agency, and third-party intervention. Bulletin of Economic Research, 56(1), 1-20.

https://doi.org/10.1111/j.1467-8586.2004.00185.x

Standardization Administration of China. (2017). Prefabricated building evaluation standard (No. GB/T51129-2017).

Ukoha, O. M., \& Beamish, J. O. (1997). Assessment of residents' satisfaction with public housing in Abuja, Nigeria. Habitat International, 21(4), 445-460.

https://doi.org/10.1016/S0197-3975(97)00017-9

Wang, Y. W., Yuan, Z. M., \& Sun, C. S. (2018). Research on assembly sequence planning and optimization of precast concrete buildings. Journal of Civil Engineering and Management, 24(2), 106-115. https://doi.org/10.3846/jcem.2018.458

Xing, Y. Z., \& Deng, X. Y. (2017, July 28-30). Evolutionary game model study of construction green supply chain management under the government intervention. In IOP Conference Series: Earth and Environmental Science (Vol. 94), Singapore.

$\mathrm{Xu}, \mathrm{B}$. , \& Chen, J. J. (2010). Research on the measuring model of construction industrialization development level. In 2010 International Conference on Management and Service Science, Wuhan, China. https://doi.org/10.1109/ICMSS.2010.5575911

Yao, P. Z. (2018). Influence of precast rate on engineering cost of assembled shear wall structure [Master's thesis]. School of Civil Engineering, Qingdao University of Technology, Shandong, China (in Chinese).

Zhang, S., Pan, Y., Li, N., \& Sun, Q. (2014a). A comparative study of the direct costs between prefabricated housing system and the traditional construction technology - A case study of precast concrete wall panel. In Proceedings of the 18th International Symposium on Advancement of Construction Management and Real Estate (Chapter 35, pp. 349-358). Springer. https://doi.org/10.1007/978-3-642-44916-1_35

Zhang, X., Skitmore, M., \& Peng, Y. (2014b). Exploring the challenges to industrialized residential building in China. Habitat International, 41, 176-184.

https://doi.org/10.1016/j.habitatint.2013.08.005

Zheng, S. Q., Sun, W. Z., \& Xu, Y. F. (2014). Estimation methodology of public housing coverage ratio and its application in Chinese cities. Systems Engineering - Theory \& Practice, 34(11), 2791-2800 (in Chinese).

\section{APPENDIX 1}

\subsection{Analysis of the customers' revenue}

Table 1 also shows the customers' revenue from buying $\mathrm{PH}$, which is shown in Eqn (A1.1):

$$
U_{u}=x\left(R_{u}-C_{u}\right) .
$$

The customers' revenue from buying $\mathrm{CH}$ is shown in Eqn (A1.2):

$$
U_{c}=(1-x)\left(R_{c}-C_{c}\right) .
$$

\section{Let}

$$
\Delta_{2}=U_{u}-U_{c}=\left(R_{u}-C_{u}+R_{c}-C_{c}\right) x-\left(R_{c}-C_{c}\right)=0,
$$
then $\boldsymbol{x}^{*}$ is shown as Eqn (A1.3):

$$
x^{*}=\frac{R_{c}-C_{c}}{R_{u}-C_{u}+R_{c}-C_{c}} .
$$

At this time, if developers have a probability of $x^{*}$, customers have the same revenue from $\mathrm{PH}$ and $\mathrm{CH}$. If developers have a probability larger than $x^{*}$, customers will choose to buy $\mathrm{PH}$.

If the government provides subsidy $F$ for customers, then customers will obtain the extra $F$ when buying $\mathrm{PH}$. The new revenue is shown as Eqn (A1.4):

$$
U_{u}^{\prime}=x\left(R_{u}-C_{u}+F\right) \text {. }
$$

The expected revenue from buying $\mathrm{CH}$ remains the same.

Then, let

$\Delta_{2}^{\prime}=U_{u}^{\prime}-U_{c}=\left(R_{u}-C_{u}+R_{c}-C_{c}+F\right) x-\left(R_{c}-C_{c}\right)=0$, and

$$
x^{\prime}=\frac{R_{c}-C_{c}}{R_{u}-C_{u}+R_{c}-C_{c}+F}<x^{*} .
$$

\subsection{Analysis of the customers' replicator dynamics equation}

According to Table 2, customers' revenue from buying $\mathrm{PH}$ is shown in Eqn (A1.6):

$$
U_{21}=x\left(R_{u}-C_{u}+F\right) \text {. }
$$

The customers' revenue from buying $\mathrm{CH}$ is shown in Equation (A1.7):

$$
U_{22}=(1-x)\left(R_{c}-C_{c}\right) .
$$

The customers' expected revenue is shown in Eqn (A1.8):

$$
E_{2}=y U_{21}+(1-y) U_{22} \text {. }
$$

Then, the customers' replicator dynamics equation is shown as Eqn (A1.9):

$$
\begin{aligned}
& K(y)=\frac{d y}{d t}=y\left(U_{21}-E_{2}\right)=y(1-y)\left(U_{21}-U_{22}\right)= \\
& y(1-y)\left[x\left(R_{u}-C_{u}+R_{c}-C_{c}+F\right)-R_{c}+C_{c}\right] .
\end{aligned}
$$




\subsection{Analysis of the Jacobian matrix}

According to Section 3.3, the Jacobian matrix $J$ can be defined as Eqn (A1.10):

$$
\begin{gathered}
J=\left[\begin{array}{cc}
\frac{\partial G(x)}{\partial x} & \frac{\partial G(x)}{\partial y} \\
\frac{\partial K(y)}{\partial x} & \left.\frac{\partial K(y)}{\partial y}\right]
\end{array}\right]= \\
{\left[\begin{array}{c}
(1-2 x)\left[\left(R_{f}+R_{t}\right) y+R_{e}-R_{t}-C_{f}+C_{t}+H\right] \\
y(1-y)\left(R_{u}-C_{u}+R_{c}-C_{c}+F\right) \\
x(1-x)\left(R_{f}+R_{t}\right) \\
(1-2 y)\left(R_{u}+R_{c}-C_{u}-C_{c}+F\right) x-R_{c}+C_{c}
\end{array}\right] .}
\end{gathered}
$$

Then, the signs of the Jacobian determinant (Det $J$ ) and trace $(\operatorname{tr} J)$ can determine the stability (Eqns (A1.11) and (A1.12)):

$$
\begin{aligned}
& \text { Det } J=a_{11} a_{22}-a_{12} a_{21} ; \\
& \operatorname{tr} J=a_{11}+a_{22} .
\end{aligned}
$$

\section{APPENDIX 2}

\subsection{Proofs of Proposition 1}

According to the partial derivative of $F$ and $H$, Eqns (A2.1) and (A2.2) are positive. Then, the area of ABCD will increase with the increase in subsidies $H$ and $F$.

$$
\begin{aligned}
& \frac{\partial S_{A B C D}}{\partial F}=\frac{1}{2} \times \frac{R_{c}-C_{c}}{\left(R_{u}+R_{c}-C_{c}-C_{u}+F\right)^{2}}>0 ; \\
& \frac{\partial S_{A B C D}}{\partial H}=\frac{1}{2} \times \frac{1}{R_{f}+R_{t}}>0 .
\end{aligned}
$$

\subsection{Proof of Proposition 2}

According to the second-order partial derivative of $F$ and $H$, Eqn (A2.3) is negative, which means that the area of $\mathrm{ABCD}$ increases increasingly slowly as $F$ increases. Eqn (A2.4) is zero, which means that the area of $\mathrm{ABCD}$ increases at a stable pace $\left(\frac{1}{2\left(R_{f}+R_{t}\right)}\right)$ continuously, regardless of how much $H$ increases.

$$
\begin{aligned}
\frac{\partial^{2} S_{A B C D}}{\partial F^{2}} & =-\frac{R_{c}-C_{c}}{\left(R_{u}+R_{c}-C_{c}-C_{u}+F\right)^{3}}<0 ; \\
\frac{\partial^{2} S_{A B C D}}{\partial H^{2}} & =0 .
\end{aligned}
$$

\subsection{Proof of Proposition 3}

Because $0 \leq x^{*}, y^{*} \leq 1, F, H \geq 0$, then

$$
0 \leq \frac{R_{c}-C_{c}}{R_{u}+R_{c}-C_{c}-C_{u}+F} \leq 1
$$

$$
0 \leq \frac{R_{t}-R_{e}+C_{f}-C_{t}-H}{R_{f}+R_{t}} \leq 1 .
$$

Therefore,

$$
\begin{aligned}
& 0 \leq H \leq R_{t}-R_{e}-C_{t}+C_{f}, \\
& F \geq 0 .
\end{aligned}
$$

In reality, developers and customers are willing to choose $\mathrm{PH}$ only if the subsidy can cover the incremental costs, which means $H \geq C_{f}-C_{t}, F \geq C_{u}-C_{c}$. Therefore, $C_{f}-C_{t} \leq H \leq R_{t}-R_{e}-C_{t}+C_{f}$ and $F \geq C_{u}-C_{c}$.

\subsection{Proof of Proposition 4}

Let $\frac{\partial S_{A B C D}}{\partial F}=\frac{\partial S_{A B C D}}{\partial H}$; then, $F^{*}$ is shown as Eqn (A2.5):

$$
F^{*}=\sqrt{\left(R_{f}+R_{t}\right)\left(R_{c}-C_{c}\right)}+C_{c}+C_{u}-R_{c}-R_{u} .
$$

$F^{*}$ is related to the developers' total benefits and the customers' net benefits of $\mathrm{PH}$ and $\mathrm{CH}$. CHS should be smaller than $F^{*}$, and the probability will increase more quickly than the effect of DHS; DHS should be larger than $F^{*}$; then, the probability will increase more quickly than the effect of CHS, and the promotion will be faster (Figure 12).

In addition, $H$ must be larger than $C_{f}-C_{t}$ (Proposition 3), so the lower limit depends on which limit is larger. If $\sqrt{\left(R_{f}+R_{t}\right)\left(R_{c}-C_{c}\right)}+C_{c}+C_{u}-R_{c}-R_{u}$ is larger, the development of $\mathrm{PH}$ will be faster and better with the subsidy because the developers choose $\mathrm{PH}$ as long as the subsidy is larger than $C_{f}-C_{t}$. If $C_{f}-C_{t}$ is larger, the developers will choose $\mathrm{PH}$, and the development will immediately progress more quickly.

Therefore, the scope of $H$ is

$$
\begin{aligned}
& H \in\left[\operatorname { m a x } \left\{\sqrt{\left(R_{f}+R_{t}\right)\left(R_{c}-C_{c}\right)}+C_{c}+C_{u}-R_{c}-R_{u^{\prime}}\right.\right. \\
& \left.\left.C_{f}-C_{t}\right\}, R_{t}-R_{e}-C_{t}+C_{f}\right]
\end{aligned}
$$

and the scope of $F$ is

$$
F \in\left[C_{u}-C_{c}, \sqrt{\left(R_{f}+R_{t}\right)\left(R_{c}-C_{c}\right)}+C_{c}+C_{u}-R_{c}-R_{u}\right] .
$$

\subsection{Proof of Proposition 5}

Proof: From Figure $4 \mathrm{~d}$, it can be seen that $D\left(x^{*}, y^{*}\right)$ is a saddle point, which means that it curves up in one direction and down in a different direction. In Figure $4 \mathrm{~d}$, points $A$ and $C$ go up to point $D$, while point $D$ goes to points $O$ and $B$; finally, the stable points are $O(0,0)$ and $B(1,1)$. If the developers and customers are willing to choose $\mathrm{PH}$, the beginning point should be above point $D$, which means that if $x \geq x^{*}$ and $y \geq y^{*}$, then both developers and customers will tend to choose PH. Therefore, when the probabilities of developers and customers reach $x^{*}$ and $y^{*}$, respectively, the government no longer needs to offer the subsidies; developers and customers are willing to choose 
$\mathrm{PH}$ actively later. At this point, it is reasonable for the government to save financial expenditure even though the development speed is slower without subsidies. According to Eqns (16) and (18), $x^{*}$ and $y^{*}$ are related to $F$ and $H$, respectively.

\section{APPENDIX 3}

\subsection{Maintenance cost}

Traditional buildings need repair every 15 years, while prefabricated buildings need repair every 20 years. During the lifetime (50 years) of the buildings, Building A needs repair 3 times and the costs are 2, 2.5 and 3.5 million yuan, respectively; while Building $B$ needs repair twice and the costs are 1 and 1.5 million yuan, respectively. Therefore, the net present value (NPV) of the maintenance cost of A is 4.051 yuan $/ \mathrm{m}^{2}$, and that of B is 14.122 yuan $/ \mathrm{m}^{2}$.

\subsection{Scrap cost}

According to the experts, the scrap cost of traditional buildings is $3 \%$ of the cost of construction, while the scrap cost of prefabricated buildings is $10 \%$ of the cost of construction. Therefore, the NPV of the scrap cost of A is 1.583 yuan $/ \mathrm{m}^{2}$ while that of $B$ is 3.972 yuan $/ \mathrm{m}^{2}$.

\subsection{Weights of the benefits by AHP}

The weights of the benefits are determined using the AHP based on a survey of 24 experts in the field of cast-in-site buildings and 24 experts in prefabricated buildings. Figure A3.1 is the index of the benefits. Based on the expert survey, the weights of the benefits are shown in Table A3.1. Then, the weights of the social benefit and satisfaction can be calculated compared to the economic benefit in the same dimensions and units.

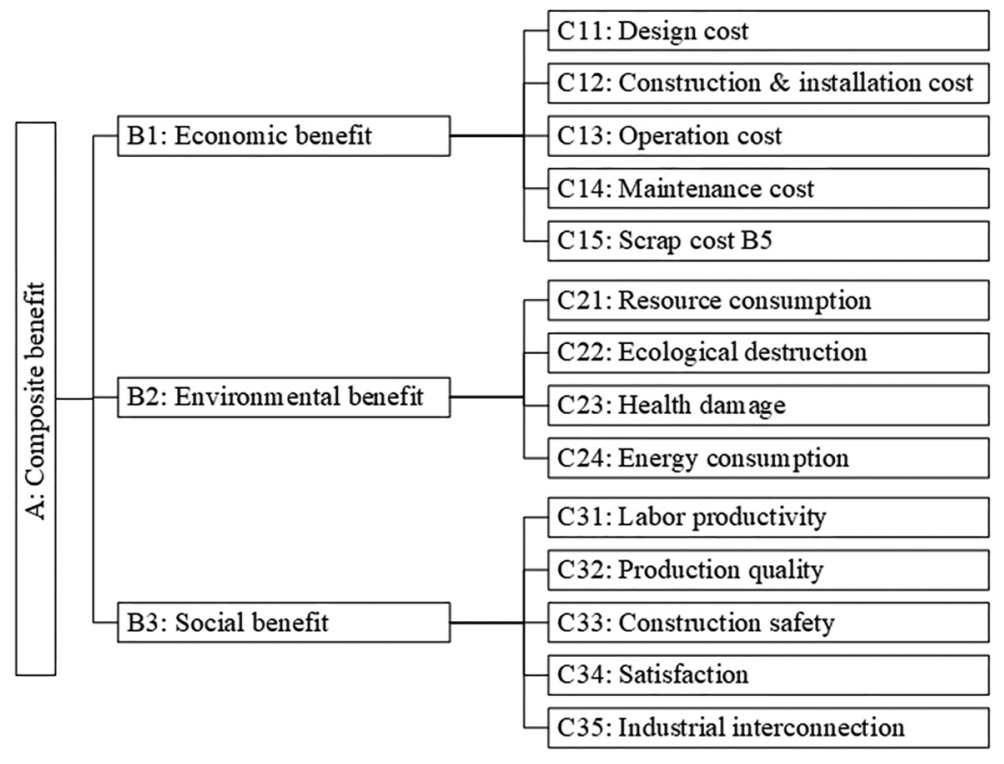

Figure A3.1. Index of the benefits

Table A3.1 The weights of the benefits

\begin{tabular}{|l|c|c|c|}
\hline Building & Matrix & Weight & Eigenvector \\
\hline \multirow{4}{*}{$\begin{array}{l}\text { Cast-in-site } \\
\text { buildings }\end{array}$} & $\mathrm{B} 1-\mathrm{B} 3$ & $\mathrm{~W}_{\mathrm{A} 0}$ & $(0.687,0.187,0.126)$ \\
\cline { 2 - 4 } & $\mathrm{C} 11-\mathrm{C} 15$ & $\mathrm{~W}_{\mathrm{A} 1}$ & $(0.546,0.142,0.209,0.064,0.039)$ \\
\cline { 2 - 4 } & $\mathrm{C} 21-\mathrm{C} 24$ & $\mathrm{~W}_{\mathrm{A} 2}$ & $(0.413,0.137,0.145,0.305)$ \\
\cline { 2 - 4 } & $\mathrm{C} 31-\mathrm{C} 35$ & $\mathrm{~W}_{\mathrm{A} 3}$ & $(0.246,0.158,0.390,0.130,0.076)$ \\
\hline \multirow{4}{*}{$\begin{array}{l}\text { Prefabricated } \\
\text { buildings }\end{array}$} & $\mathrm{B} 1-\mathrm{B} 3$ & $\mathrm{~W}_{\mathrm{B} 0}$ & $(0.648,0.230,0.122)$ \\
\cline { 2 - 4 } & $\mathrm{C} 11-\mathrm{C} 15$ & $\mathrm{~W}_{\mathrm{B} 1}$ & $(0.146,0.317,0.407,0.098,0.032)$ \\
\cline { 2 - 4 } & $\mathrm{C} 21-\mathrm{C} 24$ & $\mathrm{~W}_{\mathrm{B} 2}$ & $(0.203,0.233,0.159,0.405)$ \\
\cline { 2 - 4 } & $\mathrm{C} 31-\mathrm{C} 35$ & $\mathrm{~W}_{\mathrm{B} 3}$ & $(0.149,0.350,0.230,0.130,0.141)$ \\
\hline
\end{tabular}

